\title{
Progressing Towards More Quantitative Analytical Pyrolysis of Soil Organic Matter Using Molecular Beam Mass Spectroscopy of Whole Soils and Added Standards
}

*Michelle L. Haddix ${ }^{\mathrm{a}}$, Kim Magrini-Bair ${ }^{\mathrm{b}}$, Robert J. Evans ${ }^{\mathrm{c}}$, Richard T. Conant ${ }^{\mathrm{a}}$, Matthew D. Wallenstein $^{\mathrm{a}}$, Sherri J. Morris ${ }^{\mathrm{d}}$, Francisco Calderón ${ }^{\mathrm{e}}$, Eldor A. Paul ${ }^{\mathrm{a}, \mathrm{f}}$

\author{
${ }^{a}$ Natural Resource Ecology Laboratory, 200 West Lake Street, Colorado State University, Fort \\ Collins, CO 80523-1499 USA \\ ${ }^{\mathrm{b}}$ National Renewable Energy Laboratory, 15013 Denver West Parkway, Golden, CO 80401-3305 \\ USA
}

${ }^{\mathrm{c}}$ MicroChem Technologies Inc., 8999 W. Harvard Pl., Lakewood, CO, 80227-6106

${ }^{\mathrm{d}}$ Biology Department, Bradley University, 1501 W. Bradley Avenue, Peoria, IL 61625 USA

${ }^{\mathrm{e} U S D A}$ ARS, Cent Great Plains Res Stn, Akron, CO 80720 USA

${ }^{\mathrm{f}}$ Department of Soil and Crop Sciences, 200 West Lake Street, Colorado State University, Fort Collins, CO 80523-1499 USA

*Corresponding author: Phone: (970) 491-6162; Fax: (970) 491-1965; E-mail:

michelle.haddix@colostate.edu

\section{Abstract}

3 Soil organic matter (SOM) is extremely complex. It is composed of hundreds of different organic

4 substances and it has been difficult to quantify these diverse substances in a dynamic- ecosystem

5 functioning standpoint. Analytical pyrolysis has been used to compare chemical differences

6 between soils, but its ability to measure the absolute amount of a specific compound in the soil is

$7 \quad$ still in question. Our objective was to assess whether utilizing pyrolysis-molecular beam mass 
8 spectroscopy (py-MBMS) to define the signature of known reference compounds (adenine,

9 indole, palmitic acid, etc.) and biological samples (chitin, fungi, cellulose, etc.) separately and

10 when added to whole soils it was possible to make py-MBMS more quantitative. Reference

11 compounds, spanning a wide variety of compound categories, and biological samples, expected

12 to be present in SOM, were added to three soils from Colorado, Ohio, and Massachusetts that

13 have varying total C, \% clay, and clay type. Py-MBMS, a rapid analysis technique originally

14 developed to analyze complex biomolecules, flash pyrolyzes soil organic matter to form products

15 that are often considered characteristic of the original molecular structure. Samples were

16 pyrolyzed at $550^{\circ} \mathrm{C}$ by py-MBMS. All samples were weighed and $\% \mathrm{C}$ and $\% \mathrm{~N}$ determined both

17 before and after pyrolysis to evaluate mass loss, $\mathrm{C}$ loss, and $\mathrm{N}$ loss for the samples. An average

18 relationship of $r^{2}=0.76(P=0.005)$ was found for the amount of cellulose added to soil at 25,50 ,

19 and $100 \%$ of soil $\mathrm{C}$ relative to the ion intensity of select mass/charge of the compound. There

20 was a relationship of $r^{2}=0.93(P<0.001)$ for the amount of indole added to soil at 25,50 , and

$21100 \%$ of soil $\mathrm{C}$ and the ion intensity of the associated mass variables (mass/charge). Comparing

22 spectra of pure compounds with the spectra of the compounds added to soil and isolated clay

23 showed that interference could occur based on soil type and compound with the Massachusetts

24 soil with high $\mathrm{C}\left(55.8 \mathrm{~g} \mathrm{C} \mathrm{kg}^{-1}\right)$ and low \% clay (5.4\%) having the least interference and the

25 Colorado soil with low $\mathrm{C}\left(14.6 \mathrm{~g} \mathrm{C} \mathrm{kg}^{-1}\right)$ and a moderate smectite clay content of $14 \%$ having the

26 greatest soil interference. Due to soil interference from clay type and content and varying

27 optimum temperatures of pyrolysis for different compounds it is unlikely that analytical

28 pyrolysis can be quantitative for all types of compounds. Select compound categories such as

29 carbohydrates have the potential to be quantified in soil with analytical pyrolysis due to the fact

30 that they: 1) almost fully pyrolyzed, 2) were represented by a limited number of $\mathrm{m} / \mathrm{z}$, and 3) had 
31 a strong relationship with the amount added and the total ion intensity produced. The three

32 different soils utilized in this study had similar proportions of C pyrolyzed in the whole soil (54-

$3357 \%$ ) despite differences in \% $\mathrm{C}$ and \%clay between the soils. Mid-infrared spectroscopic

34 analyses of the soil before and after pyrolysis showed that pyrolysis resulted in reductions in the

$353400,2930-2870,1660$ and $1430 \mathrm{~cm}^{-1}$ bands. These bands are primarily representative of $\mathrm{O}-\mathrm{H}$

36 and $\mathrm{N}-\mathrm{H}$ bonds, $\mathrm{C}-\mathrm{H}$ stretch, and $\delta\left(\mathrm{CH}_{2}\right)$ in polysaccharides/lipid and are associated with

37 mineralizable SOM. The incorporation of standards into routine analytical pyrolysis allowed us

38 to assess the quantitative potential of py-MBMS along with the effect of the mineral matrix,

39 which we believe is applicable to all forms of analytical pyrolysis.

40 Keywords:

41 Analytical pyrolysis, molecular beam mass spectroscopy, soil organic matter chemistry, 42 pyrolysis standards

44 1. Introduction molecular weight, structural complexity, mean residence times and interactions with the mineral

47 soil matrix. It is challenging to describe and quantify the full diversity of these substances.

48 Thus, they are often aggregated into classes of compounds with similar properties. Most

49 physical and chemical methods used to determine different SOM components are time intensive

50 and produce only operationally-defined information that may not always represent meaningful

51 identities. The application of new techniques has revealed that the classic operationally-defined

52 'lignin' fraction determined by acid digestion (Klason lignin) contains an abundance of non-

53 lignin compounds (Preston et al., 2009). The methods used to fractionate and characterize SOM 
54 have a critical influence on conceptual paradigms of SOM formation, decomposition, and

55 functionality. As new techniques have emerged, they have required us to revisit and revise

56 paradigms such as the contribution of humic substances (Kelleher \& Simpson, 2006), the

57 recalcitrance of lignin (Preston et al., 2009), the contribution of microbial constituents to SOM

58 formation (Kelleher \& Simpson, 2006; Miltner et al., 2012), and the role of the soil matrix to soil

59 formation and dynamics (Paul, 2015; Grandy et al., 2009).

Analytical pyrolysis (py) has been widely applied to structural studies of synthetic and

61 biologic macromolecules. The transfer of thermal energy to the polymeric network or

62 macromolecule causes physical cleavage of the chemical bonds and yields pyrolysis products

63 that can be related back to the original structures. When coupled with gas chromatographic mass

64 spectroscopic (GC/MS) detection, it has often been used in a variety of studies to characterize

65 SOM and has proven very useful in providing insight into a wide range of questions relating to

66 soil. Pyrolysis-gas chromatography-mass spectroscopy (Py-GC/MS) separates volatile pyrolysis

67 species on a GC column before MS analysis. It is a powerful technique that requires selecting a

68 column designed for specific analyte classes (hydrocarbons, oxygenates, aromatics) and it is

69 possible that not all pyrolyzates are separated on a given column. Py-GC/MS has been used to

70 characterize peat (Calvert et al., 1989), humic acids (Saiz-Jimenez \& de Leeuw, 1986; González-

71 Pérez et al., 2011), burned soils (De la Rosa et al., 2008), soil fractions (Buurman \& Roscoe,

72 2011), allophanic soils (Buurman et al., 2007) and SOM from different ecosystems

73 (Vancampenhout et al., 2009). Field ionization mass spectroscopy (py-FIMS) in which mg

74 quantities of sample are directly introduced into the ion source of the mass spectrometer with no

75 prior separation, has revealed differences in SOM between tillage treatments (Sleutel et al.,

76 2007), the soil rhizosphere (Gillespie et al., 2009), soil fractions (Schnitzer \& Schulten, 1992; 
77 Leinweber \& Schulten, 1995), seasonal variations (Leinweber et al, 1994), and SOM formation

78 over time (Schulten et al., 1992). A related approach to py-FIMS couples analytical pyrolysis

79 with molecular beam mass spectroscopy (py-MBMS), which has the advantage of high sample

80 throughput and rapid measurement of high molecular weight product signals compared to

81 GC/MS methods (Evans \& Milne, 1987). Unlike GC/MS data, pyrolysis mass spectra are very

82 complex and representative of all species in the pyrolyzate. Multivariate data analysis (pattern

83 recognition) is generally used to process the large spectral data sets and identify trends to

84 discover the underlying chemical changes that may not be obvious by comparison of such

85 complex mass spectra (Evans \& Milne, 1987; Windig et al.,1987; Agblevor et al., 1994).

86 Magrini et al. (2002) and Hoover et al. (2002) used py-MBMS to distinguish differences between

87 SOM based on depth, site, and revegetation. It has also been used to distinguish between native

88 and cultivated soils and soil fractions (Plante et al., 2009; Haddix et al., 2011) and relate

89 pyrolysis characteristics to SOM content, particulate organic matter C, mineral C, and soil

90 microbial biomass $\mathrm{C}$ in native prairie soils (Magrini et al., 2007).

91 Analytical pyrolysis provides a wealth of compound identification, but is usually

92 considered semi-quantitative. One reason for this is that different compounds have different

93 pyrolytic responses and some compounds when pyrolyzed are released as secondary by-products

94 that cannot be ascribed to their original compounds (Schulten, 1996), but the use of reference

95 compounds can aide in understanding this issue and help us to determine if certain types of

96 compounds can be quantified (Schellekens et al., 2015). A second reason for this method being

97 considered semi-quantitative is that not all SOM is pyrolyzed due to different optimal pyrolysis

98 temperatures for different compounds (Saiz-Jimenez, 1994) along with the modification of

99 organic matter during the heating process (Miltner \& Zech, 1997) possibly producing thermally 
100 stable char, which needs to be considered when evaluating quantification. Also the method of

101 detection can limit the quantitative ability. Py-GC/MS has the advantage of more thorough

102 compound identification but only pyrolysis products that are GC separable are detected (Saiz-

103 Jimenez, 1994; Dignac et al., 2006). Py-FIMS, and py-MBMS are considered more quantitative

104 due to their ability to detect a larger suite of compounds that are directly introduced into the mass

105 spectrometer (Derenne \& Quénéa, 2015). If whole soil are being pyrolyzed the mineral matrix

106 can interfere with the pyrolysis process causing problems with quantification. This interference

107 can be caused by clays, Fe and Al oxides, and carbonates (Faure et al., 2006a; Faure et al.,

108 2006b; Spaccini et al., 2013). While in some cases clays can increase cracking activity (produce

109 less complex pyrolyzates) and make it difficult to associate pyrolysis products back to their

110 original compounds, useable pyrolyzates are still generated for analysis (Magrini et al., 2007).

111 Extraction techniques that target specific organic components have been used with analytical

112 pyrolysis to minimize mineral interference. Pretreatments such as hydrofluoric acid (HF)

113 (Zegouagh et al., 2004; Rumpel et al., 2009; Spaccini et al., 2013; Suárez-Abelenda et al., 2015)

114 or humic extraction utilizing NaOH (Saiz-Jimenez \& de Leeuw, 1986; Schulten, 1996; Plante et

115 al., 2009; González-Pérez et al., 2011) can reduce interference from soil constituents and isolate

116 organic matter, but these methods can also cause issues with quantification. HF can cause C

117 losses from 7-30\% during treatment of surface soils and forest horizons (Skjemstad et al., 1994;

118 Schmidt et al., 1997; Mathers et al., 2002; Rumpel et al., 2006) and losses up to 80-92\% in

119 subsurface soils (Dai \& Johnson, 1999; Rumpel et al., 2002). HF pretreatments can also cause

120 biases due to chemical alteration of the SOM (Dai \& Johnson, 1999; Rumpel et al., 2006; Sleutel

121 et al., 2009). Extraction by $\mathrm{NaOH}$ isolates up to $80 \%$ of organic matter (Stevenson, 1994), but

122 there is some debate about the prevalence of humics in soil (Kelleher \& Simpson, 2006) and if 
123 they are the product of the extracting media (Klebler \& Johnson, 2010; Lehmann \& Kleber, 124 2015).

125 Previous work has found that $5-12 \%$ of the soil mass is lost during pyrolysis (Sorge et 126 al., 1993a; Sleutel et al., 2007) and that 47-99\% of total C and N pyrolyzes in soil and soil 127 fractions (Leinweber \& Schulten, 1995; Schulten \& Leinweber, 1999). This wide range of 128 values is dependent on pyrolysis temperature, \%C, and soil type. Extensive $m / z$ score 129 identification lists, which do not differ greatly with the type of instrumentation, have been 130 published for reference compounds (Buurman \& Roscoe, 2011; Schulten, 1996).

131 The use of complementary analysis such as XANES and NMR in conjunction with 132 analytical pyrolysis has shown similarities in composition between compounds identified 133 utilizing different methods (Kaal et al., 2007; Gillespie et al., 2009; Leinweber et al., 2010). We 134 need to determine the relationships between the mass spectroscopic signals from reference 135 compounds expected to be present in SOM and the total ion intensity produced to better measure 136 the quantity as well as the type of SOM constituents. It is also necessary to establish the mass 137 loss and amount of $\mathrm{C}$ and $\mathrm{N}$ pyrolyzed in different soils as this will aid in our quantification 138 ability. Clays have an important effect on the amount of soil organic matter present in soil. 139 Additionally, the impact of soils with varying properties such as clay content, \% $\mathrm{C}, \mathrm{Fe}$ and $\mathrm{Al}$ 140 oxides, etc. on the type and amounts of pyrolysis products needs to be established when 141 pyrolyzing whole soil samples. Our approach in this study is to add compounds representative of 142 the building blocks most commonly found in SOM with the expectation that we can relate select $143 \mathrm{~m} / \mathrm{z}$ from these standards back to actual amounts in the soil. Along with this we will measure 144 mass loss with pyrolysis and the effect of the mineral matrix to evaluate if we can improve 145 quantification of analytical pyrolysis. 
A recent review of analytical pyrolysis-based instrumental techniques characterized py-

147 MBMS as a quantitative analysis (Derenne \& Quénéa, 2015) though a need to further investigate

148 the quantitative degree of py-MBMS is warranted. The objective of this study was to investigate

149 the degree of quantification achievable with py-MBMS in order to quantify SOM compounds

150 within the soil matrix along with determining the effect of the soil matrix in different soils.

151 Specifically, we aimed to answer the questions: 1) Can we associate specific mass spectral data

152 reported as $m / z$ scores to a specific reference compound or compound category? 2) Is there a

153 strong relationship between select $\mathrm{m} / \mathrm{z}$ and the amount of an added compound in a sample? 3)

154 What is the degree of mineral interference for various compounds and soil types? 4) What

155 compounds are and are not pyrolyzed? The answers to these questions begin to lay a foundation

156 for the use of py-MBMS, and other analytical pyrolysis techniques, as a quantitative SOM

157 analysis tool.

159 2. Material and methods

160 2.1. Sample Sites

161 We utilized three soils that we have previously studied (Haddix et al., 2011; Plante et al., 162 2009) with varying $\mathrm{C}, \mathrm{N}, \mathrm{pH}$, and clay content and type (Table 1). The Akron soil with $14.6 \mathrm{~g} \mathrm{C}$

$163 \mathrm{~kg}^{-1}$ and a moderate smectite clay content of $14 \%$ was collected from USDA-ARS Central Great 164 Plains Research Station $\left(40^{\circ} 09^{\prime} \mathrm{N}, 103^{\circ} 08^{\prime} \mathrm{W}\right)$ near Akron, Colorado. The Akron soil is an 165 Aridic Paleustoll (Halvorson et al., 1997) and was collected to a depth of 0-20 cm in native 166 grassland with a mix of $\mathrm{C}_{3}$ and $\mathrm{C}_{4}$ grasses. There were three separate sampling pits within the 167 grassland area, each treated as a separate replicate. 
The Hoytville soil with $24.8 \mathrm{~g} \mathrm{C} \mathrm{kg}^{-1}$ and high clay content (35.9\%), comprised of illite,

169 was from the Ohio Agricultural Research Development Center near Hoytville, Ohio ( $41^{\circ} 00^{`} \mathrm{~N}$,

$\left.17084^{\circ} 00^{\prime} \mathrm{W}\right)$. This soil is a Mollic Ochraqualfs that has been under continuous corn since 1962

171 after the removal of the deciduous forest and installation of tile drainage. The site is in no-till

172 and has an extensive proportion of high mean residence time soil organic matter associated with

173 the clay fraction (Paul et al., 2001; Haile-Mariam et al., 2008). This site has three plot replicates

174 and multiple composited cores were taken from each plot to a depth of $0-20 \mathrm{~cm}$. The clay

175 fraction used in this study was fractionated from the Hoytville soil by shaking the soil with $0.5 \%$

176 sodium hexametaphosphate and glass beads for 18 hours and then centrifuging the dispersed

177 sample at $200 \mathrm{~g}$ for $2 \mathrm{~min} 56 \mathrm{sec}$ after which the clay supernatant was aspirated off and dried at

$17860^{\circ} \mathrm{C}$.

179 The Waltham soil was collected from the Boston Area Climate Experiment (BACE) in

180 Waltham, Massachusetts $\left(40^{\circ} 23^{\prime} \mathrm{N}, 71^{\circ} 13^{\prime} \mathrm{W}\right)$. This has a higher $\mathrm{C}$ content $\left(55.8 \mathrm{~g} \mathrm{C} \mathrm{kg}^{-1}\right) \mathrm{but}^{\prime}$

181 only $5.4 \%$ clay. The site is now a grassland on an abandoned agricultural field, which was

182 originally deciduous forest. The soil is a Mesic Typic Dystrudept (Haven series) (Suseela et al.,

183 2012). This site has three plot replicates and multiple, composited cores were taken from each

184 plot to a depth of $0-5 \mathrm{~cm}$.

185

186 2.2. Sample Preparation and Compound Standards

187 Soils were prepared by removing large plant materials, sieved to $2 \mathrm{~mm}$, oven dried at 60

$188{ }^{\circ} \mathrm{C}$, and finely ground prior to analysis. Total $\mathrm{C}$ and $\mathrm{N}$ content was determined with a LECO

189 CHN-1000 autoanalyzer (LECO Corporation, St. Joseph, MI, USA). The absence of carbonates 
190 was confirmed using a fizz test, so total $\mathrm{C}$ in the soils was determined to be organic $\mathrm{C}$. The $\mathrm{pH}$ of 191 soils was determined using 1:1 soil to water slurry solution (Thomas, 1996).

192 We utilized pure reference compounds that were readily available through manufacturers

193 and biological samples that were purchased through manufacturers or isolated from biological

194 materials (Table 2). The reference compounds spanned a variety of compound categories utilized

195 in other studies (Schulten, 1996; Hempfling \& Schulten, 1990) that we are using as model

196 compounds to represent some of the hundreds of compounds that are common in SOM. The

197 biological samples were chosen to represent actual biological components we would expect to

198 find in SOM. The reference and biological samples were run on the py-MBMS by themselves

199 and mixed with soil. The reference compounds and biological samples were added to each soil

200 in an amount to increase the total $\mathrm{C}$ content of the sample by 50\%. Fifty percent of soil $\mathrm{C}$ was

201 chosen to make sure the added compound had a detectable signal, but was not greater than the

202 soil SOM signal. Cellulose and indole were added to the soil in three different concentrations

203 (standard addition) to increase the soil C content by 25,50 , and $100 \%$. Cellulose was also added

204 to an isolated, clay-sized fraction from the Hoytville soil to determine clay interference. All

205 solid standards added to dry soil were mixed with each soil using a mortar and pestle. The

206 bacteria sample (Escherichia coli) was in a dilute liquid growth broth and was added to the soil

207 drop-wise just prior to analysis. The original spectra for the reference samples shown in Table 2

208 are shown in Supplemental Fig. 1.

209

210 2.3. Instrument Analysis

211 Samples were analyzed using py-MBMS (Magrini et al., 2002; Hoover et al., 2002).

$212 \quad 100-200 \mathrm{mg}$ of soil and 5-20 mg samples of standard were run in duplicate or triplicate 
213 replicates. All soils and standards were oven dried at $60{ }^{\circ} \mathrm{C}$ prior to analysis except indole and 214 palmitic acid which were placed in a desiccator for 24 hours prior to analysis, due to their low 215 melting point. Samples were weighed in quartz boats and pyrolyzed until the total ion intensity 216 returned to background levels, which was approximately three minutes, in a reactor consisting of 217 a quartz tube $\left(2.5 \mathrm{~cm}\right.$ inside diameter) with helium flowing through at $5 \mathrm{~L} \mathrm{~min}^{-1}$ heated and 218 maintained at $550{ }^{\circ} \mathrm{C}$. The quartz reactor was connected to the sampling orifice of the molecular 219 beam mass spectrometer (MBMS). The system utilized an Extrel TM model TQMS C50 for 220 analysis of the pyrolysis vapors. Residence time of the vapors was short enough to minimize 221 secondary reactions in the quartz reactor (Evans \& Milne, 1987; Plante et al., 2009). Mass 222 spectral data from $\mathrm{m} / \mathrm{z} 20$ to 625 were acquired on a Teknivent Vector 2TM data acquisition 223 system using $22 \mathrm{eV}$ electron impact ionization and programmed storage in a personal computer.

224 Repetitive scans (one $480 \mathrm{amu} \mathrm{scan} \mathrm{s}{ }^{-1}$ ) were recorded during the evolution of a pyrolysis wave 225 from each soil sample and then averaged across all scans. For all spectra, a blank spectra signal 226 was subtracted prior to any data analysis. Compound category summaries were calculated by 227 using published compound categories and associated $m / z$ data (Schulten et al., 1986; Hempfling 228 \& Schulten, 1990; Schulten, 1996; Magrini et al., 2007; Sykes et al., 2008; Gillespie et al., 2009)

229 along with validation from our standards. For the few instances when one $\mathrm{m} / \mathrm{z}$ was associated 230 with more than one compound category, the ion intensity of that $m / z$ was split equally between 231 the two categories.

232 With the exception of the cellulose and indole regressions, signals from individual 233 samples were standardized to $100 \%$ total ion intensity (TII), which corrects for differences in 234 sample size and $\mathrm{C}$ content. The amount of mass loss during pyrolysis was determined by 235 weighing the sample before and after pyrolysis. The $\mathrm{C}$ content of soil and pyrolyzed residues 
was determined using a Carlo Erba NA 1500 Elemental Analyzer (Carlo Erba, Milan, Italy). To

237 determine the amount of added compound pyrolyzed in soil it was assumed that the same amount

238 of soil $\mathrm{C}$ was pyrolyzed with and without compound addition. Thus, the additional C pyrolyzed

239 was assumed to be from the added compound.

240 Pyrolyzed and whole (not pyrolyzed) samples from Akron and Hoytville soils were

241 scanned neat on the mid-infrared (MIR) range of 4000 to $400 \mathrm{~cm}^{-1}$ on a Digilab FTS 7000

242 (Agilent Technologies, Walnut Creek, CA) with a Peltier-cooled DTGS detector, KBr beam

243 splitter, and KBr background. The samples were scanned in diffuse reflectance mode, and

244 resolution was set at $4 \mathrm{~cm}^{-1}$, with 64 co-added scans. Prior calibration of the instrument was done

245 using many of the same standards utilized in this study (Calderón et al., 2013). The

246 SUBTRACT.AB application of GRAMS/AI version 9.1 software (Thermo Fisher, Woburn, MA)

247 was used to perform the spectral subtractions of whole minus pyrolyzed soil spectra. This

248 subtraction uses the algorithm described by Banerjee and Li (1991). The resulting spectrum

249 equals the whole soil spectrum minus the pyrolyzed soil spectrum multiplied by a subtraction

250 factor. We used the default factor and tolerance values calculated by the software.

252 2.4. Statistical Analysis

253 Individual spectra were visually inspected for outliers and then analytical replicates from 254 py-MBMS were averaged for each sample and all statistical analysis was done on the three field 255 replicates for each soil. Comparisons between reference compounds and biological standards 256 mass spectral data were done using non-metric multidimensional scaling (NMS) for $m / z, 57-625$ 257 (PC Ord version 6.0 MjM Software, Gleneden Beach, OR). NMS does not assume that the data 258 is normal or that there are linear relationships among variables (McCune and Grace, 2002). For 
NMS the Sørensen (Bray-Curtis) coefficient was used for calculating distance measures with a

260 random seed and 50 runs with real data. Comparisons between pure compound spectrum to

261 soil+compound were done by subtracting the standardized spectrum of the soil from the

262 standardized soil+compound spectrum. The positive portion of the difference $\operatorname{spectra}(\mathrm{m} / \mathrm{z}$ scores

263 associated with the pure compound) was then re-standardized to $100 \%$ and the ion intensity of

264 each $m / z$ from the pure compound was compared to the re-standardized compound spectra when

265 added to soil. When cellulose and indole where added to the soil in different amounts,

266 comparisons were made between ion intensity of peaks isolated using NMS for indole that was

$267 m / z$ 89, 90, 117, and 118 (Fig. 1) and for cellulose that was $m / z$ 60, 73, 89, 144 (Fig. 2).

268 Statistical analysis of amount C pyrolyzed between the soils was done using the ANOVA

269 procedure in SAS (v9.3) by soil.

\section{3. Results}

272 3.1. Reference Compounds and Biological Samples

273 For this study we utilized a wide range of compounds that spanned many general

274 compound categories found in whole soils. We had two compounds in the alkylaromatic

275 category, caffeic acid and tannic acid, with $34 \%$ of the total ion intensity (TII) being associated

276 with the primary and secondary peaks for tannic acid and $22 \%$ for caffeic acid (Table 2). Five

277 compounds comprised the carbohydrate category with the most complex being cellulose (Fig.

278 3a). Cellulose had the greatest percent of TII from the two dominant peaks of the five

279 compounds totaling $20 \%$. The two sugars, ribose and xylose, behaving similarly and had the

280 lowest percent TII at 7\% each. Cellulose, a crystalline glucose polymer, and cellobiose, a

281 soluble glucose dimer, had similar spectra with $m / z, 60$ (levoglucosan) and $m / z$ 73 (C5, C6 
282 sugars) having similar total ion intensity for their dominant peaks (Table 2). Multiple peaks

283 were associated with all or many of the compounds in the carbohydrate category with all five

284 compounds having $\mathrm{m} / \mathrm{z} 73$ in the top 5 peaks and all but xylose having $\mathrm{m} / \mathrm{z} 57$ in the top 5 peaks.

285 Indole, a heterocyclic N compound, had $64 \%$ of its TII associated with its two dominant peaks

286 (amu) and the primary peak corresponded with its molecular weight of 117 (Fig. 3b). The 12

287 compounds comprising the proteins, peptides, amino acids, and nucleic acids category had TII

288 associated with the two dominant peaks that varied from 3-70\% (Table 2). The pure amino

289 acids, alanine, glycine, and methionine, and nucleobases, adenine and guanine, resulted in clear

290 definable spectra whereas the more complex compounds like the proteins- bovine serum, casein,

291 and egg, and the enzyme urease had complex spectra with many $\mathrm{m} / z$ scores associated with very

292 little TII or uninformative spectra where many of the major $\mathrm{m} / \mathrm{z}$ scores are associated with $\mathrm{m} / \mathrm{z}$

293 less than 56 (Supplemental Fig. 1). We did not see similar $\mathrm{m} / z$ scores or percent TII between the

294 three proteins with bovine serum protein having 17\% of TII associated with the two dominant

295 peaks, although only $\mathrm{m} / \mathrm{z} 61$ is diagnostic for identification, and the egg protein was associated

296 with higher weight $\mathrm{m} / \mathrm{z}$ scores, but little TII associated with any single $\mathrm{m} / \mathrm{z}$. Casein provided the

297 least useful information with the most abundant $\mathrm{m} / \mathrm{z}$ scores being low weight and low TII

298 associated with any one $\mathrm{m} / \mathrm{z}$. There were seven compounds where the primary peak

299 corresponded to the molecular weight and these compounds fell into five different compound

300 categories (Table 2).

301 The biological samples tended to have fairly complex spectra with numerous $\mathrm{m} / \mathrm{z}$

302 products and a low percent of the total ion intensity attributed to primary and secondary peaks,

303 with the exception of bovine protein and cellulose (Fig. 3a) (Table 2). For example, the morel

304 mushroom had $1.7 \%$ of the total ion intensity (TII) associated with $\mathrm{m} / \mathrm{z} 110$ which has been 
identified as a furaldehyde (Van Smeerdijk, 1987; Hempfling \& Schulten, 1990) or a

306 dihydroxybenzene (Van Smeerdijk, 1987). The furans can have a microbial origin and large

307 amounts of furans tend to be produced with pyrolysis of fungal biomass (Gutierrez et al., 1995),

308 but $m / z, 110$ can also be associated with compounds of a non-microbial origin. The second peak,

$309 \mathrm{~m} / \mathrm{z} 280$, represented $1.6 \%$ of the TII, which has been identified as a C20:1 alkene (Gillespie et

310 al., 2009; Hempfling \& Schulten, 1990). Along with these $m / z$ scores, there were a total of 49

$311 \mathrm{~m} / \mathrm{z}$ scores that represented at least $0.5 \%$ of TII for the morel mushroom (Fig. 3c). 2-and 3-

312 furaldehyde and 5 methyl 2-furaldehyde can be pyrolysis products of microbial organic matter

313 (Buurman et al, 2007) and so we would expect $\mathrm{m} / \mathrm{z}, 110$ and 97 to be high in the bacteria sample

314 and fungal samples. We did find $\mathrm{m} / \mathrm{z} 110$ to be a major peak in the morel mushroom spectrum,

315 but not in the shiitake mushroom or bacteria samples (Table 2). In the shitake the two $\mathrm{m} / \mathrm{z}$ scores

316 combined represent $1.9 \%$ of the total ion intensity and in the bacteria these two peaks combined

317 contribute $1.5 \%$ to the total ion intensity.

318 We utilized non-metric multidimensional scaling (NMS) to isolate unique $m / z$ associated

319 with the different reference compounds and biological samples. The NMS for the reference

320 compounds had a two dimensional solution recommended and stabilized after 40 iterations with

321 a final stress of 9.9 and the two dimensions accounted for $72 \%$ of the variance (Fig. 1). Indole

322 and adenine separated out from the other compounds (Fig. 1a) and $\mathrm{m} / \mathrm{z}$ scores 89, 90, 117, and

323118 being associated with indole and comprising $88 \%$ of the TII and $\mathrm{m} / \mathrm{z}$ scores 135,136 , and

324270 being associated with adenine and comprising $78 \%$ of the TII (Fig. 1b). The carbohydrates

325 clustered together (cellobiose (Clo), glucuronic acid ( $\mathrm{Gr})$, ribose $(\mathrm{Rb})$, xylose $(\mathrm{Xy})$ ), but were

326 clustered next to many of the compounds from the proteins, peptides, amino acids, and nucleic

327 acids category (arginine (Ar), asparagine (As), glucosamine (Gs), glycine (Gy)) so NMS does 
not separate out any distinct $\mathrm{m} / \mathrm{z}$ for these compounds (Fig. 1a). Guanine and vanillin cluster together due to the same $m / z$ (151 and 152) being associated with both compounds, but they are

330 from different compound categories. Both palmitic acid and tannic acid separate from the cluster

331 of compounds with distinct $m / z$ being associated with each.

A two dimensional solution was recommended for the NMS analysis of the biological

333 samples with a final stress of 4.5 after 61 iterations and the two dimensions explaining $75 \%$ of

334 the variance (Fig. 2). The NMS for the biological samples shows separation of cellulose, bovine

335 protein, and lignin (Fig. 2a). There were four $m / z$ associated with cellulose $(60,73,89$, and 144)

336 comprising $24 \%$ of the TII (Fig. 2b). The $m / z$ scores 61 and 62 had the greatest association with

337 the bovine protein and account for $12 \%$ of the TII in that compound. The $m / z$ scores 332,386 ,

338 and 418 appear to have the greatest association with the isolated poplar lignin, but those $\mathrm{m} / \mathrm{z}$

339 scores only account for $2 \%$ of the TII in lignin. Chlorophyll also separated out and was

340 associated with multiple high molecular weight $\mathrm{m} / \mathrm{z}$ and the microbial samples clustered together

341 (Bacteria (Ba), Morel (Mo), Shiitake (Sh)).

343 3.2. Sample Quantification

344 Cellulose and indole were added to the Akron and Hoytville soils in different amounts to

345 determine the relationship between the ion intensity of select $\mathrm{m} / \mathrm{z}$ scores and the amount of

346 compound added. For both cellulose and indole, the $m / z$ most associated with each compound

347 using NMS, for indole that was 89, 90, 117, 118 and for cellulose that was 60, 73, 89, 144 (Fig. 1

348 and 2), were summed and the TII of the soil for those peaks subtracted from the soil with added

349 compound. This was then compared with the amount of reference sample $\mathrm{C}$ added. There was a

350 relationship of $r^{2}=0.691(P=0.006)$ for cellulose in Akron soil and $0.837(P<0.001)$ between the 
351 amount of cellulose $\mathrm{C}$ added to the Hoytville (Fig. 4a), indole had an $r^{2}=0.941(P<0.001)$ and $3520.924(P<0.001)$ (Fig. 4b) for Akron and Hoytville respectively. Cellulose was added in only 353 one concentration to the Waltham soil, but the one addition amount was included in Fig. 4a to 354 illustrate the much higher ion intensity count for cellulose that occurred in that low clay soil. 355 Using the regression equation for cellulose to estimate carbohydrate $\mathrm{C}$, we calculate an average $356 \quad 1.7 \mathrm{~g} \mathrm{C} \mathrm{kg}^{-1}$ in the Akron soil representing $11 \%$ of the total SOC. The $3.4 \mathrm{~g} \mathrm{C} \mathrm{kg}^{-1}$ calculated 357 carbohydrate $\mathrm{C}$ in the Hoytville soil accounts for $14 \%$ of the SOC of this sample. The difference spectra (Fig. 3a versus Fig. 5a, b, and c) show the impact of soil 359 composition on the cellulose pyrolysis spectra. For the difference spectra, all the positive peaks 360 are associated with cellulose and all negative peaks are associated with the soil. Many of the 361 dominant $\mathrm{m} / \mathrm{z}$ scores in the pure compound were also found in the difference spectra (above the 362 line) although at a lower percent TII. The positive portion of the difference diagram for both 363 Hoytville and Waltham showed fairly similar spectra to pure cellulose. However $\mathrm{m} / \mathrm{z} 126$, a small 364 percentage in pure cellulose, was found in the positive portion in spectra for all soils as well as 365 clay (Fig. 5). Akron also had an addition of $m / z, 110$ in the cellulose spectra (Fig. 5a). The clay 366 fraction appears to produce more differences with the reduction of $m / z 60$ (Fig. 5d) showing the 367 influence of both soils and clay on the $m / z$ scores.

368 To understand the effect of different soils on signal interference, we plotted the percent 369 TII in our standard cellulose against the percent TII of the cellulose added to soil. With this 370 method, a slope of one would indicate no soil interference. Akron and Hoytville soils show a 371 reduction of the total ion intensity for cellulose when added to soil, as shown by regression lines 372 below the 1:1 line (Fig. 6a, b). The $m / z$ 60, which is the primary pyrolysis peak of cellulose, is 373 still the primary peak in the Akron and Hoytville soil plus cellulose, but $\mathrm{m} / \mathrm{z}, 73$ is no longer the 
374 secondary peak. The Waltham soil, in contrast, has little to no soil interference with a regression 375 very similar to the 1:1 line (Fig. 6c) and a slope of 1.20 and a $r^{2}$ of 0.947 (Table 3). The isolated 376 clay produced the greatest interference with a regression well below the 1:1 line with a slope of 3770.29 and an $r^{2}$ of 0.20 . None of the dominant peaks found in pure cellulose were dominant peaks 378 in cellulose-clay mixtures (Figs. $5 \mathrm{~d}$ and $6 \mathrm{~d}$ ). This result as well shows differences in the 379 fragmentation of the pyrolysis products likely due to cracking from the clay. Recovery equations (coefficient of determinations and slopes) were calculated for the 381 compounds and biological materials added to the soils (Table 3). The relationships varied 382 greatly between compounds with $r^{2}$ values from 0.02 to 0.96 . Some of the more complex 383 biological materials like chlorophyll and morel mushroom tended to have lower $r^{2}$ though the 384 shiitake mushroom did not follow this trend. The Akron and Hoytville soils had very low $r^{2}$ for 385 ergosterol. It appears that the soils changed the pyrolysis characteristics of the major fungal lipid 386 ergosterol from an $m / z 396$ to 253 and 254 in Akron and 249 and 253 in Hoytville. This also 387 occurred in the Waltham soil, but to a lesser extent with the dominant peaks of the ergosterol in 388 this soil comprising $\mathrm{m} / \mathrm{z}, 378$ and 253. When these additional peaks were added to $\mathrm{m} / \mathrm{z} 396$ in 389 ergosterol, the $r^{2}$ increased in Akron from 0.02 to $0.37,0.03$ to 0.56 in Hoytville, and 0.44 to $390 \quad 0.82$ in Waltham. Although some of the more complex compounds had low $r^{2}$ and slopes, 391 adenine, egg protein, guanine, indole, and vanillin had minimal soil interference with slopes 392 similar to one and high $r^{2}$ values. Across the different compounds, the Waltham soil tended to 393 have higher $r^{2}$ and slopes closer to one, except in the case of urease, but because of the high SOC 394 content more of the standard had been added to the Waltham soil. The Hoytville soil tended to 395 have similar or higher $r^{2}$ and slopes than the Akron soil. The proteinaceous compounds that 
gave poorly defined spectra had coefficients of determination similar to those for other

397 compounds with more defined spectra.

\subsection{Pyrolysis of Soils}

Utilizing previously characterized compound categories (Schulten et al., 1986; Hempfling

401 \& Schulten, 1990; Schulten, 1996; Magrini et al., 2007; Sykes et al., 2008; Gillespie et al., 2009)

402 and our standards, we were able to classify into compound categories $58 \%$ of the TII of the

403 pyrolysed materials in the Akron soil, $61 \%$ in the Hoytville soil, and $78 \%$ in the Waltham soil

404 (Fig. 7). These results suggest that the Waltham soil had different SOM constituents or possibly

405 less interference of the mineral constituents as was also seen with the added standards (Table 3).

406 Summing the individual peaks into classes on the basis of our standards and literature show that

407 for the Waltham soil the $\mathrm{N}$ compounds and proteins, peptides, amino acids, and nucleic acids

408 categories contributed the most to the TII at $18 \%$ each with the next largest category being

409 carbohydrates at $17 \%$ (Fig. 7c). Compared to the other two soils, Waltham had more total

410 carbohydrates, proteins, peptides, amino acids, and nucleic acids, as well as phenols and lignin

411 monomers than the Akron and Hoytville soils and less unidentified compounds (Fig. 7).

412 Although the Akron and Hoytville soils have visibly different py-MBMS spectra, the

413 summarized total ion intensities for the compound categories are similar for the two soils (Fig. 7a

$414 \& \mathrm{~b})$.

415

416 3.4. Characterization of Pyrolyzed Soil Samples and Standards

417 Pyrolysis caused 8\% mass loss in the Hoytville soil and between 14.9 and $15.8 \%$ in the

418 Akron, Waltham, and the Hoytville clay fraction (Table 4). The amount of C pyrolyzed, 
corrected for mass loss, was 53 to $57 \%$ and was not statistically significant between the soils or

420 the clay fraction. Fifty-one to $100 \%$ of the reference compounds and biological samples added

421 to soil were pyrolyzed, but there was high variability associated with some of these estimates

422 (Table 5). The amount of sample pyrolyzed differed between the standards, but tended to be

423 similar between the soils, except for urease where Akron had 77\% of the standard pyrolyzed and

424 Waltham had $96 \%$ of the standard pyrolyzed. Cellulose and palmitic acid both pyrolyzed almost

425 completely in all three soils with values ranging from 96-100\% in cellulose and 94-100\% in

426 palmitic acid. Indole pyrolyzed at a much lower percentage, from 51-70\% (Table 5). These

427 compounds are completely pyrolyzed when analyzed alone and palmitic acid has been correlated

428 with soil microbial biomass (Magrini et al., 2007). Both results suggest that minimal interaction

429 occurs with these compounds during py-MBMS analysis of whole soils.

430 Characterization of the whole and pyrolyzed Hoytville soil by MIR showed that

431 pyrolysis caused reductions in absorbance at 3400, 2930-2870, 1660, and $1430 \mathrm{~cm}^{-1}$ (Fig. 8a).

432 This is consistent with the SOM in the samples losing $\mathrm{O}-\mathrm{H}$ and $\mathrm{N}-\mathrm{H}$ bonds (3400), C-H stretch

433 (2930-2870), and $\delta\left(\mathrm{CH}_{2}\right)$ in polysaccharides/lipid (1430) (Movasaghi et al., 2008). Absorbance

434 at $1660 \mathrm{~cm}^{-1}$ has been attributed to amide I-like absorption $(\mathrm{C}=\mathrm{O} / \mathrm{C}-\mathrm{N})$ or aromatic $\mathrm{C}=\mathrm{C}$, but it

435 should be noted that other moieties and minerals can complicate this assignment. Absorbance at

$436 \quad 1270-1370 \mathrm{~cm}^{-1}$, which encompasses bands for $\mathrm{C}-\mathrm{O}$ stretch and $\mathrm{CH}$ overtones, increased in the

437 pyrolyzed soil relative to the whole soil (Fig. 8a). The Akron spectra of the whole and pyrolyzed

438 soils showed similar changes to the Hoytville soil (Fig. 8b), suggesting that pyrolysis has

439 consistent results across agricultural soils. 
443 quantitative tool for understanding the chemistry of SOM. There are many aspects involved in

444 achieving a more quantitative analysis, but the four that we focused on were 1) can we associate

445 specific $\mathrm{m} / \mathrm{z}$ scores to a specific compound or compound category? 2) is there a strong

446 relationship between select peaks and the amount of compound in a sample? 3) what is the

447 degree of mineral interference for various compounds and soil types? 4) what compounds are 448 and are not pyrolyzed?

449 For the first aspect, associating specific $\mathrm{m} / \mathrm{z}$ scores to specific compounds, the type of 450 mass spectrometric analysis used will play a role in this objective. Py-MBMS sacrifices more 451 detailed identification compared to py-GC/MS for the ability to detect a larger suite of

452 compounds. The increased number of peaks in py-MBMS can complicate interpretation because 453 multiple compounds can be associated with the same $\mathrm{m} / \mathrm{z}$. With respect to compound categories, 454 the cyclic N compound, indole, had a large amount of the total ion intensity (TII) associated with 455 a few distinct peaks which allowed it to separate from the other compounds on NMS, making it 456 promising for quantification, however, other compounds in this class need to be investigated.

457 Both alkylaromatic compounds also had a significant amount of total ion intensity associated 458 with only a few peaks, but more compounds need to be assessed to see if this trend continues.

459 The carbohydrate category and cellulose individually are promising for quantitative analysis with 460 many of the same $m / z(60,73)$ being associated with all or most of the compounds compared, a 461 fair amount of TII being associated with a few $\mathrm{m} / \mathrm{z}$ scores, and a clustering of these compounds 462 in NMS, but $m / z$ scores from carbohydrates can also be associated with compounds in other 463 categories. The two sugars studied had a lower amount of TII associated with the two largest 464 peaks. Some carbohydrates have been found to pyrolyze at temperatures lower than $550{ }^{\circ} \mathrm{C}$ 
465 (Syverud et al., 2003) which may be causing the low TII for the two sugars. Although secondary

466 reactions can occur during the pyrolysis of cellulose (Pastorova et al., 1994; Saiz-Jimenez,

467 1994), we still see a distinct spectra associated with a limited number of $m / z$. We studied a large

468 number of compounds in the protein, peptide, amino acid, nucleic acid category and as an entire

469 category there is a significant amount of variability in the ion traces that make quantification

470 difficult. The ability to accurately quantify proteins in soil would be useful, but with limited

471 informative $\mathrm{m} / \mathrm{z}$ scores being consistently associated with the proteins and low TII associated

472 with $\mathrm{m} / \mathrm{z}$ scores this does not appear feasible. Phenols and alkyl-phenols are signature

473 compounds for proteins, but the same components are found after pyrolysis of lignins, cellulose,

474 or humic substances (Stuczynski et al., 1997), which might be indicative of why there are not

475 distinctive peaks found for the proteins. During protein pyrolysis, secondary reactions can occur

476 and the range of pyrolysis products increases as the variety of building units increases with a

477 large number of unknown compounds (Saiz-Jimenez, 1994), which also contributes to the

478 difficulty in identifying protein pyrolyzates. The amino acids and nucleobases within this larger

479 group did give consistent and promising results for quantification and should be investigated

480 further. Reference compounds like cellulose, indole, palmitic acid, and tannic acid where the

481 majority of the total ion intensity is associated with a limited number of distinct $\mathrm{m} / \mathrm{z}$ scores may

482 be the most useful starting compounds to quantify compounds in soil.

483 Quantification of bacteria, fungi, and total microbial biomass is useful when trying to

484 understand SOM changes and dynamics. There are pyrolysis products associated with microbial

485 biomass such as 2-and 3-furaldehyde and 5 methyl 2-furaldehyde (Buurman et al, 2007), but

486 complex biological samples like bacteria and the fungi (morel and shiitake) have numerous $\mathrm{m} / \mathrm{z}$

487 scores and very little of the TII associated with any one $m / z$. The bacteria sample was in a dilute 
growth broth so that may have also attributed to the numerous peaks as sodium and other ions

489 could crack pyrolysis products. The spectra from microbes are different enough from SOM to

490 indicate that although pyrolysis may not be useful for biomass determinations, it should have

491 some use in the estimation of the role of microbial productions in SOM formation.

Different compounds have optimal pyrolysis temperatures (Saiz-Jimenez, 1994) which

493 makes quantification of a variety of compounds difficult at a single pyrolysis temperature. We

494 utilized $550{ }^{\circ} \mathrm{C}$ as a pyrolysis temperature for it tends to be a suitable temperature for biomass

495 pyrolysis (Syverud et al., 2003), but if quantification of a specific compound category is desired

496 modification of pyrolysis temperature should be considered to optimize for that compound.

497 Pyrolysis temperatures of $550-650^{\circ} \mathrm{C}$ have been found to be good ranges for pyrolyzing

498 carbohydrates (Syverud et al., 2003) whereas temperatures as high as $770{ }^{\circ} \mathrm{C}$ may be necessary

499 to study more resistant macromolecules (Saiz-Jimenez et al., 1987).

$500 \quad$ The second aspect in achieving quantification is understanding the relationship between

501 selected peaks and the amount of compound in a sample. This was only investigated with indole

502 and cellulose as both compounds showed promise with a high percentage of TII associated with

503 a only few distinct $\mathrm{m} / \mathrm{z}$ scores. Both cellulose and indole had robust relationships between the

504 amount of compound added and the ion intensity of the two dominant peaks for both the Akron

505 and Hoytville soils. Both soils had similar, although slightly different, relationships possibly

506 indicative of soil interference (likely clay). Relationships may need to be developed for

507 individual soil types in order to accurately quantify the amount of a specific compound in a soil.

508 The solid relationship between the intensity of selected peaks and amount of compound added to

509 the sample as well as the similar regressions between the soils indicates the usefulness of this

510 approach for quantitative analysis if the complexities involved are taken into consideration. Our 
511 estimation of the amount of total carbohydrates in the two soils using the cellulose standard was

512 very similar to the amount of total carbohydrates estimated in our soils using the summation of

$513 \mathrm{~m} / \mathrm{z}$ associated with carbohydrates with a 3-4\% difference in the values. It is important to note

514 that there may be some differences in residence time and microbial and fungal processing

515 between the pyrolysis of a pure compound like cellulose versus native carbohydrates in soil. A

516 study by Syverud et al. (2003) was able to quantify carbohydrate amounts in chemical pulps

517 utilizing py-GC/MS, supporting the idea of quantification of certain compound categories.

518 Utilizing an approach taken by Sorge et al. (1993b) where 23 amino acid standards were run on

519 py-GC/MS and py-FIMS and then 12 different $\mathrm{m} / \mathrm{z}$ scores were used to quantify $\alpha$-amino $\mathrm{N}$ in

520 soil may also be a useful approach to quantify other well resolved compounds in soil.

521 The third aspect to consider for more quantitative analysis is the degree of mineral

522 interference for various compounds and soil types. Clay minerals can act as a catalyst during the

523 pyrolysis process and cause the formation of secondary artifacts in pyrolysates (Faure et al.,

524 2006a; Faure et al., 2006b; Spaccini et al., 2013), but the actual amount of interference for

525 quantitative analysis has not been adequately established nor has whether the same breakdown

526 products are always formed. Studies have found that during pyrolysis the clay minerals cause the

527 new formation of aromatic units such as alkylbenzene and polycyclic aromatic hydrocarbons

528 with increasing smectite causing the aliphatic chains to disappear and in parallel a relative

529 enrichment in aromatic structures occurs (Faure et al., 2006a). The effect of clay on pyrolysis

530 transformation can vary between compounds with a wax ester having limited bond breakage in

531 the presence of clay compared to an alkanol and an alkanoic acid (Nierop and van Bergen, 2002).

532 This result could be due to the more stable aliphatic bonds in long chain hydrocarbons compared

533 with the more labile oxygenates. 
Mineral components have been shown in other studies to be a controlling factor when

535 pyrolyzing carbohydrate containing biomass (Evans \& Milne, 1987; Sorge et al., 1993a; Faure et

536 al., 2006a). We utilized cellulose as an example of how the spectrum changes from the pure

537 standard when added to different soils. The TII of the dominant $\mathrm{m} / \mathrm{z}$ scores of cellulose are

538 reduced in the presence of soil and there was an increase in some of the secondary $\mathrm{m} / \mathrm{z}$ scores.

539 The increases in $\mathrm{m} / \mathrm{z}, 110$ and 126 when cellulose was added to soil and clay also occurred in

540 another study utilizing py-MBMS (Evans \& Milne, 1987). When we pyrolyzed cellulose with

541 the isolated clay size fraction, the spectrum associated with cellulose was greatly altered. The

542 addition of alkali material is thought to favor the release of furfural instead of levoglucosan and

543 lead to a product state composed of furfural derivatives (Evans \& Milne, 1987). The changes in

544 the cellulose spectrum varied between the three soils and the clay isolate with the Waltham soil,

545 which had the highest \%C and lowest clay content having minimal soil interference.

546 Regression analysis was performed for a variety of compounds to better understand the

547 degree of soil interference among compounds. The degree of soil interference varied between

548 the three soils and between the various compounds. Compounds like guanine and indole had

549 high $r^{2}$ values and slopes close to one for both Akron and Hoytville, indicating limited soil

550 interference, whereas compounds like chlorophyll and ergosterol had low $r^{2}$ values and slopes

551 for all soils. Interestingly tannic acid, which is a fairly complex compound, had a relatively high

552 coefficient of determination. Compounds that have minimal soil interference are good

553 candidates for quantification, such as cellulose, guanine, indole, palmitic acid, and tannic acid.

554 In our three example soils the Waltham soil with high \% $\mathrm{C}$ and low \% clay tended to have the

555 least amount of soil interference. The Akron soil with moderate clay content had the greatest

556 degree of soil interference, so contrary to Faure et al. (2006a) higher clay content doesn't 
557 necessary lead to more soil interference and suggests that the clay composition may also

558 contribute to cracking degree. Faure et al. (2006b) found that the clay type played a large role in

559 the degree of aromatization that occurred during the pyrolysis process with Na-smectite having

560 the greatest modification influence. The clay in the Akron soil is smectite and that may be the

561 reason for that soil exhibiting the most soil interference. Although it is important to point out

562 that even with the higher soil interference in Akron there is still a strong relationship between the

563 amount of cellulose and indole added to this soil and the TII associated with the respective

564 peaks. The variation in interference between soils indicates that comparisons of SOM bound to

565 the mineral matrix between soils of vastly different characteristics should be done with caution.

566 Soils having higher interference during pyrolysis have less potential for quantification and may

567 only be considered semi-quantitative. Caution should be taken with these soils and possibly only

568 comparisons within a soil type should be done.

569 Not all of the organic matter in soil is pyrolyzed and this makes quantification difficult

570 because we need to know what is and is not being pyrolyzed and if different compounds

571 categories have different pyrolysis efficiencies. This issue causes us to consider the first part of

572 our fourth objective: what compounds are pyrolyzed. Organic matter components that are fully

573 pyrolyzed will provide the most accurate quantification. Compounds like cellulose and palmitic

574 acid were essentially completely pyrolyzed, whereas indole which had high $r^{2}$ s when added to

575 soil had only $51-70 \%$ of the standard pyrolyzed. We did not see a systematic difference in the

576 amount of standard pyrolyzed between the soils, although there was high variability in the

577 estimate of amount pyrolyzed, but this may mean that the mineral constituents have limited

578 effect on the amount of organic matter pyrolyzed. Standards added to the soil may not pyrolyze 
579 the same as organic matter bound to the mineral matrix, so our results may only give us a

580 potential estimation of what may be occurring in the soil matrix itself.

$581 \quad$ Sorge et al. (1993a), utilizing py-FIMS on whole soils, measured $4.7 \%$ mass loss during

582 pyrolysis and Sleutel et al. (2007) measured 8-12\% mass loss during pyrolysis. Our mass loss of

$5838-15 \%$ is similar to the range seen by Sleutel et al. (2007). Other studies using py-MBMS have

584 shown a greater range of mass volatilized during pyrolysis (6\% to 25\%) (Plante et al., 2009). We

585 found that $53-57 \%$ of the soil $\mathrm{C}$ was pyrolyzed compared to previous work on litter where $68-$

$58678 \%$ of $\mathrm{C}$ was pyrolyzed using the same pyrolysis conditions (Wallenstein et al., 2013). This

587 amount of \%C volatilized is quite similar to the $57 \%$ of $\mathrm{C}$ volatilized in soil by Leinweber and

588 Schulten (1995) using py-FIMS. Schulten and Leinweber (1999) found that different amounts of

589 C volatilized in different size and density fractions and hypothesized that the non-pyrolyzable

590 fraction was a thermally stable fraction of mineral-bound organic matter. Some of the non-

591 pyrolyzable material may be $\mathrm{C}$ bound to the mineral matrix, although not exclusively, since not

592 all plant $\mathrm{C}$ is pyrolyzed (Wallenstein et al., 2013). Pyrolysis can modify organic matter during

593 the heating process (Miltner \& Zech, 1997) possibly producing char, so the material remaining

594 after pyrolysis may be a combination of inherently and modified thermally stable organic matter.

595 The pyrolysis temperature and degree of heat transfer to the sample greatly determines the types

596 and amounts of compounds pyrolyzed (Saiz-Jimenez, 1994) with pyrolysis temperatures as high

597 as $770{ }^{\circ} \mathrm{C}$ utilized to study more resistant macromolecules, such as aliphatic biopolymers (Saiz-

598 Jimenez et al., 1987). With that in mind it is important to use caution when comparing pyrolysis

599 amounts from studies that utilized different pyrolysis temperatures, in different mineral matrices.

600 In this study, 43 to $47 \%$ of the soil $\mathrm{C}$ was not volatilized by pyrolysis, prompting us to

601 ask the question of what is the C chemistry of the pyrolysis-resistant material undetected by py- 
602 MBMS, which is the second part of our fourth objective in this study. For this purpose, we

603 scanned the un-pyrolyzed soils and pyrolyzed soils in MIR. One important assumption is that the

604 organic material remaining with the pyrolyzed soils is made up of the temperature resistant

605 organic matter. We recognize that a portion of the pyrolyzed organics could have been modified

606 by the $550{ }^{\circ} \mathrm{C}$ pyrolysis temperature, but with the extremely rapid heating along with the free jet

607 expansion minimizing interactions among the pyrolyzates we believe that modification is

608 minimal. This pyrolysis temperature can be considered a moderate pyrolysis temperature that

609 may not fragment more resistant moieties though it is possible that chemical transformations take

610 place especially with respect to complex carbohydrates. Even so, characterizing the pyrolyzates

611 may yield information this is related to compound recalcitrance. For example, previous studies

612 have shown that higher temperatures are needed in order to properly pyrolyze acid-resistant

613 humic acids (Saiz-Jimenez et al., 1987). The spectral changes during py-MBMS are consistent

614 with loss of thermolabile organic functional groups during dehydrogenation and dehydration

615 reactions (Schnitzer and Hoffman, 1965). The MIR shows that N-containing functional groups

616 such as amides and N-H bonds are lost, consistent with the recovery of peptide and N-containing

617 fragments as pyrolysis products. The $1370-1270 \mathrm{~cm}^{-1}$ region that showed resistance to pyrolysis

618 treatment forms a broad peak in agricultural soils (Calderón et al., 2011). While the exact nature

619 of this spectral feature is unknown, it is probably due to a combination of multiple functional

620 groups including $\mathrm{COO}$ stretch, $\mathrm{COOH}$ stretch of phenolics, amide III, and aromatic $\mathrm{C}=\mathrm{C}$.

621 Vanillin, with its highly aromatic character, absorbs at $1295 \mathrm{~cm}^{-1}$, possibly due to aromatic $\mathrm{C}=\mathrm{C}$

622 bands (Calderon et al., 2013), which suggests that the material remaining consists in part from

623 thermo-resistant, complex compounds, which are known to require temperatures to fragment and

624 leave the sample (Saiz-Jimenez, 1994). It will be interesting to determine if this spectral region, 
625 associated with resistance to pyrolysis, is also related to recalcitrance to microbial

626 decomposition. The possibility that some of these constituents were formed during the pyrolysis

627 procedure also must be considered. It is difficult to know what compounds are not being

628 pyrolyzed and the extent of modification of organic matter during the pyrolysis process.

629 Pyrolysis has been found to modify organic matter similar to oxidative decomposition patterns as

630 observed during litter decomposition (Miltner \& Zech, 1997), which makes it difficult to

631 determine if the material remaining after pyrolysis is resistant to pyrolysis or has been

632 transformed by pyrolysis. Regardless of the difficulty, it is useful to try to understand what is

633 not pyrolyzed and the incorporation of multiple analytical tools such as NMR or XANES may

634 assist in answering these questions.

635 The ability to quantify various organic matter compounds in the soil during the pyrolysis

636 process would be very valuable; especially for SOM within the soil matrix as pretreating the soil

637 to remove minerals is time consuming and can cause losses and modification to the SOM (Dai

638 and Johnson, 1999; Rumpel et al., 2006; Sleutel et al., 2009). When working with whole soils,

639 determining the degree of soil interference during pyrolysis is necessary for quantitative

640 estimates and when making comparisons across soils. Our results indicate the promise of

641 making analytical pyrolysis, specifically py-MBMS, a more quantitative approach. There are

642 compounds like cellulose and total carbohydrates that appear to fully pyrolyze, can be

643 represented by a limited number of characteristic peaks, and have strong relationship with the

644 amount added and the total ion intensity produced. Our results are specific to py-MBMS, but the

645 trends and techniques would be applicable to other analytical pyrolysis methods as well.

646 Although pyrolysis may not fully pyrolyze all organic compounds and soil interference may

647 reduce our ability to identify certain compounds, analytical pyrolysis does show promise in being 
648 quantitative for certain compound categories. In addition to using standards, py-MBMS analysis

649 can be greatly enhanced by the inclusion of complementary methods of analyzing SOM

650 molecular structure such as MIR, NMR, or thermogravimetry. Our results point to the need to

651 routinely incorporate reference standards and known biological samples into the analyses. We

652 also encourage broadly sharing data online to facilitate information exchange, so that a more

653 quantitative approach can be routinely used in the analysis of the molecular structure of SOM.

\section{Acknowledgments}

656 We would like to thank Sean Maloney for his assistance with sample preparation, Robert Sykes

657 for his assistance with instrument operation, Dr. Dukes for the use of soil from his experimental

658 site, Dr. Jessica Ernakovich for her review of this manuscript, and the valuable insights of two

659 anonymous reviewers. This research was supported by the National Science Foundation

660 Division of Environmental Biology under grant number 0842315 and the Office of Science

661 (BER), U.S. Department of Energy. Disclaimer: The use of trade, firm, or corporation names is

662 for the information and convenience of the reader. Such use does not constitute an official

663 endorsement or approval by the United States Department of Agriculture or the Agricultural

664 Research Service of any product or service to the exclusion of others that may be suitable. The

665 U.S. Department of Agriculture (USDA) prohibits discrimination in all its programs and

666 activities on the basis of race, color, national origin, age, disability, and where applicable, sex,

667 marital status, familial status, parental status, religion, sexual orientation, genetic information,

668 political beliefs, reprisal, or because all or part of an individual's income is derived from any

669 public assistance program.

670 


\section{References}

672 Banerjee, S., Li, D.Y., 1991. Interpreting multicomponent infrared-spectra by derivative

674 Buurman, P., Peterse, F., Martin, G.A., 2007. Soil organic matter chemistry in allophanic soils: a pyrolysis-GC/MS study of a Costa Rican Andosol catena. Eur. J. Soil Sci. 58, 13301347.

Buurman, P., Roscoe, R., 2011. Different chemical composition of free light, occluded light and extractable SOM fractions in soils of Cerrado and tilled and untilled fields, Minas Gerais, Brazil: a pyrolysis-GC/MS study. Eur. J. Soil Sci. 62, 253-266.

Calderón, F.J., Mikha, M.M., Vigil, M.F., Nielsen, D.C., Benjamin, J.G., Reeves, J. III, 2011. Diffuse reflectance mid infrared spectral properties of soils under alternative crop rotations in a semiarid climate. Commun. Soil Sci. Plant Anal. 42, 1-17.

Calderón, F., Haddix, M., Conant, R., Magrini-Bair, K., Paul, E., 2013. Diffuse-reflectance fourier-transform mid-infrared spectroscopy as a method of characterizing changes in soil

Dai, K.H., Johnson, C.E., 1999. Applicability of solid-state C-13 CP/MAS NMR analysis in 
thermal analysis to monitor $\mathrm{C}$ and $\mathrm{N}$ changes in soil organic matter from a Mediterranean fire

694 affected forest. Catena 74, 296-303.

695 Derenne, S., Quenea, K., 2015. Analytical pyrolysis as a tool to probe soil organic matter. J.

696 Anal. Appl. Pyrol. 111, 108-120.

697 Dignac, M.F., Houot, S., Derenne, S., 2006. How the polarity of the separation column may

698 influence the characterization of compost organic matter by pyrolysis-GC/MS. J. Anal. Appl.

$699 \quad$ Pyrol. 75, 128-139.

700 Evans, R.J., Milne, T.A., 1987. Molecular characterization of the pyrolysis of biomass.1.

$701 \quad$ Fundam. Energy Fuels 1, 123-137.

702 Faure, P., Jeanneau, L., Lannuzel, F., 2006a. Analysis of organic matter by flash pyrolysis-gas

703 chromatography-mass spectrometry in the presence of Na-smectite: When clay minerals lead 704 to identical molecular signature. Org. Geochem. 37, 1900-1912.

705 Faure, P., Schlepp, L., Mansuy-Huault, L., Elie, M., Jardé, E., Pelletier, M., 2006 b.

706 Aromatization of organic matter induced by the presence of clays during flash pyrolysis-gas

707 chromatography-mass spectrometry (PyGC-MS) - A major analytical artifact. J. Anal. Appl.

708 Pyrol. 75, 1-10.

709 Gillespie, A.W., Walley, F.L., Farrell, R.E., Leinweber, P., Schlichting, A., Eckhardt, K.U.,

710 Regier, T.Z., Blyth, R.I.R., 2009. Profiling rhizosphere chemistry: evidence from carbon and

711 nitrogen K-edge XANES and Pyrolysis-FIMS. Soil Sci. Soc. Am. J. 73, 2002-2012.

712 González-Pérez, M., Buurman, P., Vidal-Torrado, P., Martin-Neto, L., 2011. Pyrolysis-gas

713 chromatography/mass spectrometry characterization of humic acids in coastal Spodosols

714 from southeastern Brazil. Soil Sci. Soc. Am. J. 76, 961-971. 
715 Gonzélez-Pérez, J.A., Chabbi, A., de la Rosa, J.M., Rumpel, C., González-Vila, F.J., 2012.

716 Evolution of organic matter in lignite-containing sediments revealed by analytical pyrolysis

717 (Py-GC-MS). Org. Geochem. 53, 119-130.

718 Grandy, A.S., Strickland, M.S., Lauber, C.L., Bradford, M.A., Fierer, N., 2009. The influence of

719 microbial communities, management, and soil texture on soil organic matter chemistry.

720 Geoderma 150, 278-286.

721 Gutiérrez, A., Martínez, M.J., Almendros, G., González-vila, F.J., Martínez, A.T., 1995. Hyphal-

722 sheath polysaccharides in fungal deterioration. Sci. Total Environ. 167, 315-328.

723 Haddix, M.L., Plante, A.F., Conant, R.T., Six, J., Steinweg, J.M., Magrini-Bair, K., Drijber,

724 R.A., Morris, S.J., Paul, E.A., 2011. The role of soil characteristics on temperature sensitivity

725 of soil organic matter. Soil Sci. Soc. Am. J. 75, 56-68.

726 Haile-Mariam, S., Collins, H.P., Wright, S., Paul, E.A., 2008. Fractionation and long-term

727 laboratory incubation to measure soil organic matter dynamics. Soil Sci. Soc. Am. J. 72, $728 \quad 370-378$.

729 Halvorson, A.D., Vigil, M.F., Peterson, G.A., Elliot, E.T., 1997. Long-term tillage and crop

730 residue management study at Akron, Colorado, In E. A. Paul, ed. Soil Organic Matter in

731 Temperate Agroecosystems. CRC Press, Inc, pp. 361-370.

732 Hempfling, R., Schulten, H.R., 1990. Chemical characterization of the organic-matter in forest 733 soils by Curie-point pyrolysis-GC/MS and pyrolysis field-ionization mass-spectrometry. Org.

$734 \quad$ Geochem. 15, 131-145.

735 Hoover, C.M., Magrini, K.A., Evans, R.J., 2002. Soil carbon content and character in an old-

736 growth forest in northwestern Pennsylvania: a case study introducing pyrolysis molecular

737 beam mass spectrometry (py-MBMS). Environ. Pollut. 116, S269-S275. 
Kaal, J., Baldock, J.A., Buurman, P., Nierop, K.G.J., Pontevedra-Pombal, X., Martínez-Cortizas, A., 2007. Evaluating pyrolysis-GC/MS and C-13 CPMAS NMR in conjunction with a molecular mixing model of the Penido Vello peat deposit, NW Spain. Org. Geochem. 38,

Kelleher, B.P., Simpson, A.J., 2006. Humic substances in soils: Are they really chemically distinct? Environ. Sci. Technol. 40, 4605-4611.

Kleber, M., Johnson, M.G., 2010. Advances in understand the molecular structure of soil organic

747 Lehmann, J., Kleber, M., 2015. The contentious nature of soil organic matter. Nature 528, 60-68.

748 Leinweber, P., Schulten, H.R., Korschens, M., 1994. Seasonal variations of soil organic matter in 749 a long-term agricultural experiment. Plant Soil 160, 225-235.

750 Leinweber, P., Schulten, H.R., 1995. Composition, stability and turnover of soil organic-matter 751 investigations by off-line pyrolysis and direct pyrolysis mass-spectrometry. J. Anal. Appl.

$752 \quad$ Pyrol. 32, 91-110.

753 Leinweber, P., Jandl, G., Eckhardt, K.U., Kruse, J., Walley, F.L., Khan, M.J., Blyth, R.I.R., and

754 T. Regier, T., 2010. Nitrogen speciation in fine and coarse clay fractions of a Cryoboroll 755 new evidence from pyrolysis-mass spectrometry and nitrogen K-edge XANES. Can. J. Soil $756 \quad$ Sci. $90,309-318$.

757 Magrini, K.A., Evans, R.J., Hoover, C.M., Elam, C.C., Davis, M.F., 2002. Use of pyrolysis 758 molecular beam mass spectrometry (py-MBMS) to characterize forest soil carbon: method 759 and preliminary results. Environ. Pollut. 116, S255-S268. 
Magrini, K.A., Follett, R.F., Kimble, J., Davis, M.F., Pruessner, E., 2007. Using pyrolysis

761 molecular beam mass spectrometry to characterize soil organic carbon in native prairie soils.

762 Soil Sci. 172, 659-672.

763 Mathers, N.J., Xu, Z.H., Berners-Price, S.J., Perera, M.C.S., Saffigna, P.G., 2002. Hydrofluoric

764 acid pre-treatment for improving C-13 CPMAS NMR spectral quality of forest soils in

765 south-east Queensland, Australia. Aust. J. Soil Res. 40(4), 655-674.

766 McCune, B., Grace, J.B., 2002. Analysis of ecological communities. MjM Software Design, 767 Gleneden Beach, OR.

768 Miltner, A., Zech, W., 1997. Effects of minerals on the transformation of organic matter during 769 simulated fire-induced pyrolysis. Org. Geochem. 26, 175-182.

770 Miltner, A., Bombach, P., Schmidt-Brucken, B., Kastner, M., 2012. SOM genesis: microbial 771 biomass as a significant source. Biogeochemistry 111, 41-55.

772 Movasaghi, Z., Rehman, S., Rehman, I.U., 2008. Fourier transform infrared (FTIR) spectroscopy 773 of biological tissues. Appl. Spectrosc. Rev. 43, 134-179.

774 Nierop, K.G.J., van Bergen, P.F., 2002. Clay and ammonium catalyzed reactions of alkanols, 775 alkanoic acids and esters under flash pyrolytic conditions. J. Anal. Appl. Pyrol. 63, 197-208.

776 Pastorova, I., Botto, R.E., Arisz, P.W., Boon, J.J., 1994. Cellulose char structure- a combined 777 analytical PY-GC-MS, FTIR, and NMR- study. Carbohydr. Res. 262, 27-47.

778 Paul, E.A., Collins, H.P., Leavitt, S.W., 2001. Dynamics of resistant soil carbon of midwestern 779 agricultural soils measured by naturally occurring C-14 abundance. Geoderma 104, 239-256. 780 Paul, E.A., 2014. Soil Microbiology, Ecology and Biochemistry $4^{\text {th }}$ edn. Academic Press, San 781 Diego. 
782 Plante, A.F., Magrini-Bair, K., Vigil, M., Paul, E.A., 2009. Pyrolysis-molecular beam mass

783 spectrometry to characterize soil organic matter composition in chemically isolated fractions

784 from differing land uses. Biogeochemistry 92, 145-161.

785 Preston, C.M., Nault, J.R., Trofymow, J.A., 2009. Chemical Changes During 6 Years of

786 Decomposition of 11 Litters in Some Canadian Forest Sites. Part 2. (13)C Abundance,

787 Solid-State (13) C NMR Spectroscopy and the Meaning of "Lignin". Ecosystems 12,

$788 \quad 1078-1102$.

789 Rumpel, C., Kogel-Knabner, I., Bruhn, F., 2002. Vertical distribution, age, and chemical

790 composition of organic, carbon in two forest soils of different pedogenesis. Org.

$791 \quad$ Geochem. 33, 1131-1142.

792 Rumpel C., Rabia, N., Derenne, S., Quenea, K., Eusterhues, K., Kogel-Knabner, I., Mariotti, A., 793 2006. Alteration of soil organic matter following treatment with hydrofluoric acid (HF). $794 \quad$ Org. Geochem. 37, 1437-1451.

795 Rumpel, C., Chabbi, A., Nunan, N., Dignac, M.F., 2009. Impact of landuse change on the 796 molecular composition of soil organic matter. J. Anal. Appl. Pyrol. 85, 431-434.

797 Saiz-Jimenez, C., Deleeuw, J.W., 1986. Chemical characterization of soil organic-matter 798 fractions by analytical pyrolysis-gas chromatography-mass spectrometry. J. Anal. Appl. $799 \quad$ Pyrol. 9, 99-119.

800 Saiz-Jimenez, C., Deleeuw, J.W., 1987. Chemical-structure of a soil humic-acid as revealed by $801 \quad$ analytical pyrolysis. J. Anal. Appl. Pyrol. 11, 367-376.

802 Saiz-Jimenez, C., 1994. Analytical pyrolysis of humic substances- pitfalls, limitations, and 803 possible solutions. Environ. Sci. Technol. 28, 1773-1780. 
804 Schnitzer, M., Hoffman, I., 1965. Thermogravimetry of soil humic compounds. Geochim. et.

805 Cosmochim. Acta. 29, 859-870.

806 Schnitzer, M., Schulten, H.R., 1992. The analysis of soil organic-matter by pyrolysis field-

807 ionization mass-spectrometry. Soil Sci. Soc. Am. J. 56, 1811-1817.

808 Schulten, H.R., Simmleit, N., Rump, H.H., 1986. Forest damage - characterization of spruce

809 needles by pyrolysis field-ionization mass-spectrometry. International J.Environ. Anal.

$810 \quad$ Chem. 27, 241-264.

811 Schulten, H.R., Leinweber, P., Reuter, G., 1992. Initial formation of soil organic-matter from

812 grass residues in a long-term experiment. Biol. Fertil. Soils 14, 237-245.

813 Schulten, H.R., 1996. Direct pyrolysis-mass spectrometry of soils: a novel tool in agriculture,

814 ecology, forestry, and soil science, In T. W. Boutton and Y. Shin-ichi, eds. Mass

815 Spectrometry of Soils. Marcel Dekker, New York, pp. 373-436.

816 Schulten, H.R., Leinweber, P., 1999. Thermal stability and composition of mineral-bound

817 organic matter in density fractions of soil. Eur. J. Soil Sci. 50, 237-248.

818 Skjemstad, J.O., Clarke, P., Taylor, J.A., Oades, J.M., Newman, R.H., 1994. The removal of

819 magnetic-materials from surface soils- a solid-state C-13 CP/MAS NMR study. Aust. J. Soil

$820 \quad$ Res. 32, 1215-1229.

821 Sleutel, S., Kader, M.A., Leinweber, P., D'Haene, K., De Neve, S., 2007. Tillage management

822 alters surface soil organic matter composition: A pyrolysis mass spectroscopy study. Soil Sci.

823 Soc. Am. J. 71, 1620-1628.

824 Sleutel, S., Leinweber, P., Ara Begum, S., Kader, M.A., De Neve, S., 2009. Shifts in soil organic

825 matter composition following treatment with sodium hypochlorite and hydrofluoric acid.

826 Geoderma 149, 257-266. 
827 Sorge, C., Muller, R., Leinweber, P., Schulten, H.R., 1993a. Pyrolysis mass-spectrometry of

828 whole soils, soil particle-size fractions, litter materials and humic substances- statistical

829 evaluation of sample weight, residue, volatilized matter and total ion intensity. Fresenius

$830 \quad$ J.Anal. Chem. 346, 697-703.

831 Sorge, C., Schnitzer, M., Schulten, H.R., 1993b. In-source pyrolysis-field ionization mass

832 spectrometry and Curie-point pyrolysis-gas chromatography/mass spectrometry of amino

833 acids in humic substances and soils. Biol. Fertil. Soils 16, 100-110.

834 Spaccini, R., Song, X., Cozzolino, V., Piccolo, A., 2013. Molecular evaluation of soil organic

835 matter characteristics in three agricultural soils by improved off-line thermochemolysis: The

836 effect of hydrofluoric acid demineralisation treatment. Anal. Chim. Acta. 802, 46-55.

837 Stevenson, F.J., 1994. Humus chemistry. Genesis, composition, reactions, second ed. Wiley, $838 \quad$ New York.

839 Stuczynski, T.I., McCarty, G.W., Reeves, J.B., Wright, R.J., 1997. Use of pyrolysis GC/MS for 840 assessing changes in soil organic matter quality. Soil Sci. 162, 97-105.

841 Suárez-Abelenda, M., Ahmad, R., Camps-Arbestain, M., Herath, S.H.M.S.K., 2015. Changes in

842 the chemical composition of soil organic matter over time in the presence and absence of 843 living roots: a pyrolysis GC/MS study. Plant Soil 391, 161-177.

844 Suseela, V., Conant, R.T., Wallenstein, M.D., 2012. Dukes, J.S., Effects of soil moisture on the 845 temperature sensitivity of heterotrophic respiration vary seasonally in an old-field climate 846 change experiment. Glob. Chang. Biol. 18, 336-348.

847 Sykes, R., Kodrzycki, B., Tuskan, G., Foutz, K., Davis, M., 2008. Within tree variability of 848 lignin composition in Populus. Wood Sci. Technol. 42, 649-661. 
Syverud, K., Leirset, I., Vaaler, D., 2003. Characterization of carbohydrates in chemical pulps by

850 pyrolysis gas chromatography/mass spectrometry. J. Anal. Appl. Pyrol. 67, 381-391.

851 Thomas, G.W., 1996. Soil pH and soil acidity. In: D.L. Sparks, Soil Science Society of America., 852 American Society of Agronomy. (Eds.), Methods of Soil Analysis. Part 3, Chemical

853 Methods. Soil Science Society of America: American Society of Agronomy, Madison, Wis., $854 \quad$ pp. $475-490$.

855 Vancampenhout, K., Wouters, K., De Vos, B., Buurman, P., Swennen, R., Deckers, J., 2009.

856 Differences in chemical composition of soil organic matter in natural ecosystems from

857 different climatic regions - A pyrolysis-GC/MS study. Soil Biol. Biochem. 41, 568-579.

858 Van Smeerdijk, D.G., Boon, J.J., 1987. Characterization of subfossil Sphagnum leaves, rootlets

859 of ericaceae and their peat by pyrolysis high-resolution gas-chromatography mass

$860 \quad$ spectrometry. J. Anal. Appl. Pyrol. 11, 377-402.

861 Wallenstein, M.D., Haddix, M.L., Ayres, E., Steltzer, H., Magrini-Bair, K.A., Paul, E.A., 2013.

862 Litter chemistry changes more rapidly when decomposed at home but converges during 863 decomposition transformation. Soil Biol. Biochem. 57, 311-319.

864 Zegouagh, Y., Derenne, S., Dignac. M.F., Baruiso, E., Mariotti, A., Largeau, C., 2004.

865 Demineralisation of a crop soil by mild hydrofluoric acid treatment Influence on organic 866 matter composition and pyrolysis. J. Anal. Appl. Pyrol. 71, 119-135. 
870 Figure 1. Non-metric multidimentional scaling (NMS) of py-MBMS data of reference

871 compounds for $m / z$ 57-625 of scores (a) and loadings (b). Compound abbreviations are found in 872 table 2. Values are averages of two or three replicates.

873

874 Figure 2. Non-metric multidimentional scaling (NMS) of py-MBMS data of biological samples

875 for $m / z$ 57-625 of scores (a) and loadings (b). Sample abbreviations are found in table 2. Values 876 are averages of two or three replicates.

878 Figure 3. Py-MBMS spectra in percent of total ion intensity for $m / z$ 20-625 for cellulose (a), 879 indole (b), and morel mushroom (c).

881 Figure 4. Regression of amount of compound added in mg C versus ion intensity counts of 882 primary peaks for cellulose (a) and indole (b).

884 Figure 5. Relative ion intensity difference from py-MBMS for $m / z$ 57-625 between soil with 885 added cellulose minus soil for Akron (a), Hoytville (b), Waltham (c), and Hoytville isolated clay 886 fraction (d). Positive values are associated with cellulose and negative values are associated with 887 soil.

889 Figure 6. Relationships between the percent total ion intensity of each $\mathrm{m} / \mathrm{z}$ in pure cellulose and 890 in cellulose added to soil in Akron (a), Hoytville (b), Waltham (c) soils, and Hoytville clay (d). 
892 Figure 7. Py-MBMS spectra in percent of total ion intensity for $m / z$ 57-625 for Akron (a),

893 Hoytville (b), and Waltham (c) soils with the percent total ion intensity (average \pm 1 standard

894 error, $n=3$ ) summarized for each compound category in inset. Alk Arom- alkyl aromatics; Carb-

895 carbohydrates; Lipids (alkanes, alkenes, and fatty acids), Prot- peptides, proteins, nucleic acids,

896 and amino acids; Ph\&LM- phenols and lignin monomers.

897

898 Figure 8. Mid-infrared diffuse reflectance spectra of whole soil, pyrolyzed (py-MBMS) soil, and 899 subtracted whole minus pyrolyzed soil from the Hoytville (a) and Akron soil (b).

900

901 Supplemental Figure 1. Py-MBMS spectra in percent of total ion intensity of $\mathrm{m} / \mathrm{z}, 20-625$ for 902 standards and biological samples.

903 
1 Table 1 Soil characteristics of samples used for py-MBMS standards (average \pm 1 standard error, $n=3$ ).

\begin{tabular}{lclcccccc}
\hline Site & Abb. & Treatment & Mineralogical clay & $\mathbf{p H}$ & Depth $\mathbf{( c m})$ & $\mathbf{C ~ ( \mathbf { g ~ k g } ^ { - 1 } )}$ & $\left.\mathbf{~ N ~ ( g ~ k g} \mathbf{~}^{-1}\right)$ & $\% \mathbf{C l a y}$ \\
\hline Akron, CO & AK & Native grassland & Smectite & 6.7 & $0-20$ & $14.6 \pm 1.1$ & $1.73 \pm 0.05$ & $14.3 \pm 0.7$ \\
Hoytville, OH & HYT & No-till corn & Illite & 6.1 & $0-20$ & $24.8 \pm 0.4$ & $2.76 \pm 0.02$ & $35.9 \pm 0.6$ \\
Waltham, MA & WAL & Old field & Smectite/lllite & 4.6 & $0-5$ & $55.8 \pm 4.1$ & $4.68 \pm 0.27$ & $5.4 \pm 0.4$ \\
\hline Alt
\end{tabular}

2 Abb.: Name Abbreviation. 
907 Table 2 Major peaks (mass/charge) associated with various C standards and biological samples.

\begin{tabular}{|c|c|c|c|c|c|c|c|}
\hline Material & Abb. & $\begin{array}{l}\text { Compound } \\
\text { category }\end{array}$ & $\begin{array}{l}\text { Molecular } \\
\text { weight }\end{array}$ & $\begin{array}{l}\text { Primary } \\
\text { peak }(m / z)\end{array}$ & $\begin{array}{l}\text { \% Total } \\
\text { ion } \\
\text { intensity }\end{array}$ & $\begin{array}{l}\text { Secondary } \\
\text { peak }(m / z)\end{array}$ & $\begin{array}{l}\text { \% Total } \\
\text { ion } \\
\text { intensity }\end{array}$ \\
\hline & \multicolumn{7}{|c|}{ Standards } \\
\hline Adenine & Ad & Prot & 135.1 & 135 & 42.1 & 136 & 28.3 \\
\hline Alanine & $\mathrm{Al}$ & Prot & 89.1 & 44 & 34.3 & 90 & 9.2 \\
\hline Arginine & $\operatorname{Ar}$ & Prot & 174.2 & 69 & 2.8 & 134 & 2.6 \\
\hline Asparagine & As & Prot & 132.1 & 123 & 9.4 & 97 & 6.5 \\
\hline Caffeic acid & $\mathrm{Cf}$ & Alk Arom & 180.2 & 110 & 11.2 & 136 & 10.4 \\
\hline Cellobiose & Clo & Carb & 342.3 & 60 & 8.4 & 73 & 7.1 \\
\hline Ergosterol & $\mathrm{Er}$ & Sterols & 396.7 & 396 & 18.2 & 397 & 6.0 \\
\hline Glucosamine & Gs & Prot & 179.2 & 36 & 5.4 & 160 & 2.1 \\
\hline Glucuronic acid & $\mathrm{Gr}$ & Carb & 194.1 & 86 & 8.4 & 57 & 7.9 \\
\hline Glycine & Gy & Prot & 75.1 & 114 & 12.8 & 30 & 9.1 \\
\hline Guanine & $\mathrm{Gu}$ & Prot & 151.1 & 151 & 44.3 & 152 & 10.2 \\
\hline Indole & In & Heterocyclic N & 117.2 & 117 & 40.4 & 90 & 24.0 \\
\hline Methionine & $\mathrm{Me}$ & Prot & 149.2 & 149 & 8.7 & 104 & 6.7 \\
\hline Palmitic acid & $\mathrm{Pa}$ & Lipids & 256.4 & 256 & 12.0 & 257 & 9.9 \\
\hline Ribose & $\mathrm{Rb}$ & Carb & 150.1 & 73 & 3.8 & 57 & 3.6 \\
\hline Tannic acid & $\mathrm{Ta}$ & Alk Arom & 1701.2 & 126 & 20.2 & 170 & 13.4 \\
\hline Vanillin & $\mathrm{Va}$ & Ph\&LM & 152.2 & 152 & 35.5 & 151 & 16.4 \\
\hline \multirow[t]{2}{*}{ Xylose } & Xy & Carb & 150.1 & 73 & 3.9 & 96 & 3.3 \\
\hline & \multicolumn{7}{|c|}{ Biological samples } \\
\hline Bacteria & $\mathrm{Ba}$ & & & 112 & 1.5 & 152 & 1.4 \\
\hline Bovine protein & $\mathrm{BP}$ & Prot & & 61 & 11.6 & 43 & 5.4 \\
\hline Casein & $\mathrm{Ca}$ & Prot & & 44 & 3.7 & 41 & 2.1 \\
\hline Cellulose & $\mathrm{Cl}$ & Carb & & 60 & 11.9 & 73 & 8.3 \\
\hline Chitin & Ct & & & 43 & 4.2 & 84 & 3.1 \\
\hline Chlorophyll & $\mathrm{Ch}$ & & & 497 & 2.5 & 123 & 2.0 \\
\hline Egg protein & EP & Prot & & 154 & 1.6 & 138 & 1.1 \\
\hline Lignin poplar & LP & Lig Dimers & & 154 & 3.8 & 167 & 3.5 \\
\hline Morel & Mo & & & 110 & 1.7 & 280 & 1.6 \\
\hline Pectin & $\mathrm{Pe}$ & & & 126 & 4.7 & 97 & 2.8 \\
\hline Shiitake & Sh & & & 43 & 2.7 & 44 & 1.8 \\
\hline Urease & Ur & Prot & & 154 & 1.4 & 84 & 1.2 \\
\hline
\end{tabular}

908 Abb.: Name Abbreviation.

909 Alk Arom: alkyl aromatic; Carb: carbohydrates; Lipids: lipids, alkanes, alkenes, fatty acids; Prot:

910 proteins, peptides, amino acids, nucleic acids; Ph\&LM: phenols and lignin monomers. 
912 Table 3 Correlations between pure material total ion intensity and material spectra added to soil

913 total ion intensity as a means of expressing soil interference $(n=605)$.

\begin{tabular}{|c|c|c|c|c|c|c|c|c|c|}
\hline \multirow{2}{*}{$\begin{array}{l}\text { Standard/ } \\
\text { Biological samp. }\end{array}$} & \multicolumn{3}{|c|}{ Akron } & \multicolumn{3}{|c|}{ Hoytville } & \multicolumn{3}{|c|}{ Waltham } \\
\hline & $r^{2}$ & Slope & Intercept & $r^{2}$ & Slope & Intercept & $r^{2}$ & Slope & Intercept \\
\hline Adenine & 0.674 & 0.953 & 0.01 & 0.675 & 1.160 & -0.03 & & & \\
\hline Bacteria & & & & 0.560 & 0.855 & 0.02 & & & \\
\hline Casein & 0.372 & 0.609 & 0.06 & 0.397 & 0.663 & 0.06 & & & \\
\hline Cellulose & 0.623 & 0.539 & 0.08 & 0.774 & 0.729 & 0.04 & 0.947 & 1.200 & -0.03 \\
\hline Chlorophyll & 0.188 & 0.399 & 0.10 & 0.371 & 0.637 & 0.06 & & & \\
\hline Egg protein & 0.653 & 1.043 & -0.01 & 0.627 & 1.142 & -0.02 & & & \\
\hline Ergosterol & 0.020 & 0.050 & 0.16 & 0.028 & 0.100 & 0.15 & 0.444 & 0.689 & 0.05 \\
\hline Glucosamine & & & & 0.218 & 0.248 & 0.12 & & & \\
\hline Glycine & 0.658 & 0.484 & 0.09 & 0.537 & 0.580 & 0.07 & & & \\
\hline Guanine & 0.963 & 0.817 & 0.03 & 0.963 & 0.878 & 0.02 & & & \\
\hline Indole & 0.749 & 0.957 & 0.01 & 0.741 & 1.214 & -0.04 & & & \\
\hline Methionine & & & & 0.214 & 0.277 & 0.12 & & & \\
\hline Morel & 0.353 & 0.606 & 0.07 & 0.551 & 0.873 & 0.02 & & & \\
\hline Palmitic acid & 0.551 & 0.667 & 0.05 & 0.631 & 1.043 & -0.01 & 0.744 & 1.813 & -0.13 \\
\hline Shiitake & 0.506 & 0.730 & 0.04 & 0.543 & 0.965 & 0.01 & & & \\
\hline Tannic acid & 0.679 & 0.667 & 0.06 & 0.767 & 0.939 & 0.01 & & & \\
\hline Urease & 0.550 & 0.959 & 0.01 & 0.659 & 1.123 & -0.02 & 0.468 & 0.916 & 0.01 \\
\hline Vanillin & & & & 0.769 & 1.009 & 0.00 & & & \\
\hline Xylose & & & & 0.467 & 0.703 & 0.05 & & & \\
\hline
\end{tabular}


914 Table 4 Amount of mass and C lost with pyrolysis of the soils (average \pm 1 standard error, $n=3$ ).

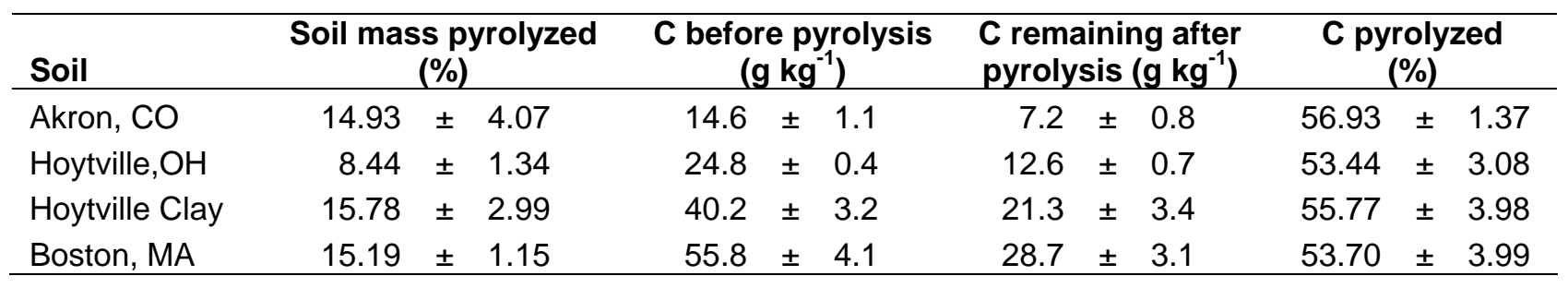

915

916 
917 Table 5 Amount of added material pyrolyzed in each soil (average \pm 1 standard error, $n=3$ ).

\begin{tabular}{|c|c|c|c|}
\hline \multirow[t]{2}{*}{$\begin{array}{l}\text { Standard/ } \\
\text { Biological samp. }\end{array}$} & \multicolumn{2}{|c|}{$\%$ of standard pyrolyzed } & \multirow[b]{2}{*}{ Waltham } \\
\hline & Akron & Hoytville & \\
\hline Casein & $76.8 \pm 8.2$ & $80.7 \pm 16.5$ & \\
\hline Cellulose & $96.2 \pm 6.6$ & $95.6 \pm 7.6$ & $100 \pm 0.0$ \\
\hline Glycine & $88.5 \pm 16.7$ & $92.1 \pm 13.7$ & \\
\hline Guanine & $73.5 \pm 23.5$ & $67.5 \pm 36.1$ & \\
\hline Indole & $69.7 \pm 11.0$ & $50.7 \pm 19.6$ & \\
\hline Morel & $72.7 \pm 25.0$ & $73.7 \pm 12.7$ & \\
\hline Palmitic acid & $94.4 \pm 4.9$ & $100 \pm 0.0$ & $98.1 \pm 3.3$ \\
\hline Shiitake & $82.2 \pm 20.7$ & $82.6 \pm 30.1$ & \\
\hline Tannic acid & $84.1 \pm 13.8$ & $71.7 \pm 12.0$ & \\
\hline Urease & $77.3 \pm 6.7$ & $85.6 \pm 12.3$ & $95.8 \pm 7.3$ \\
\hline
\end{tabular}

918

919 

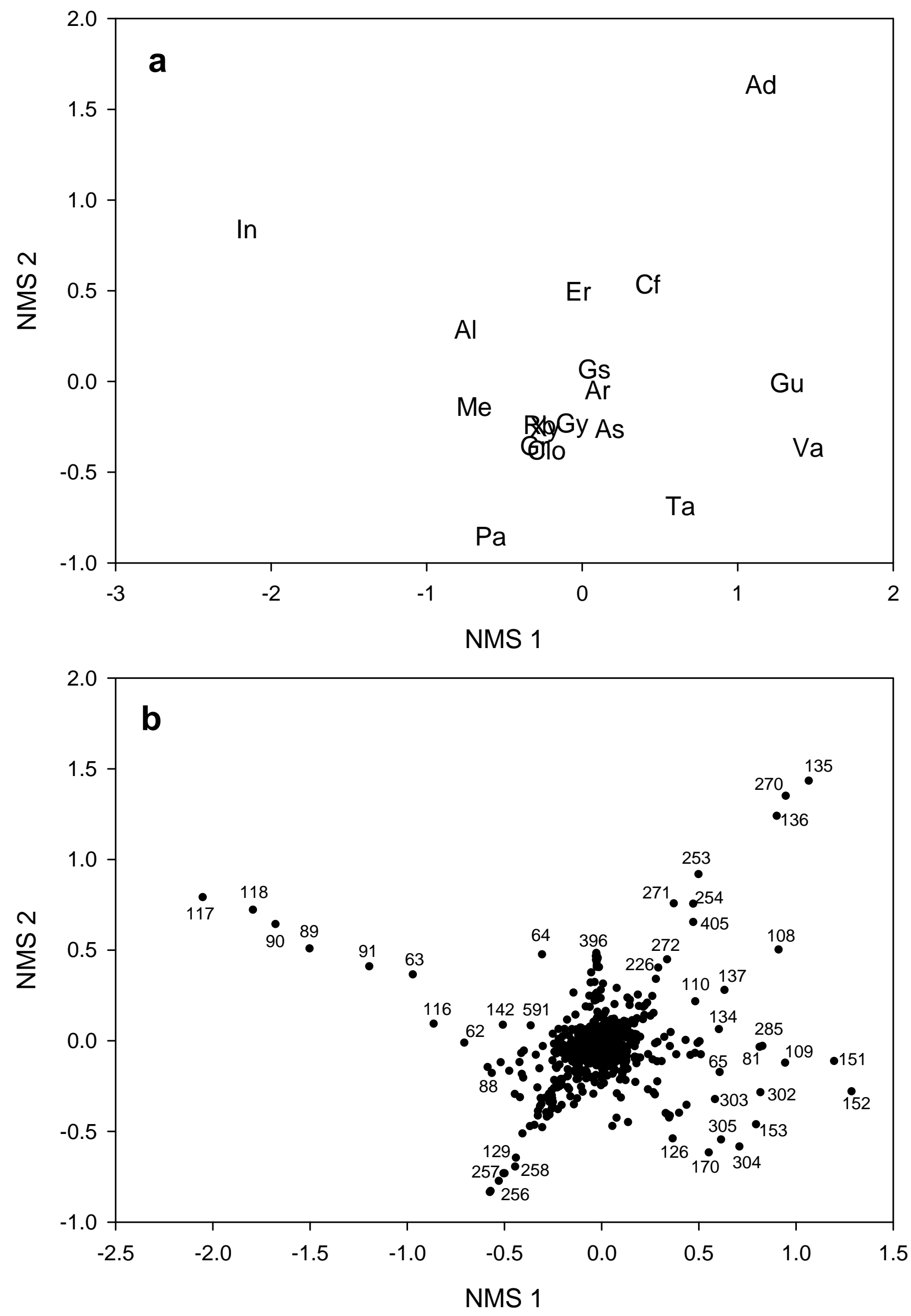

Figure 1 

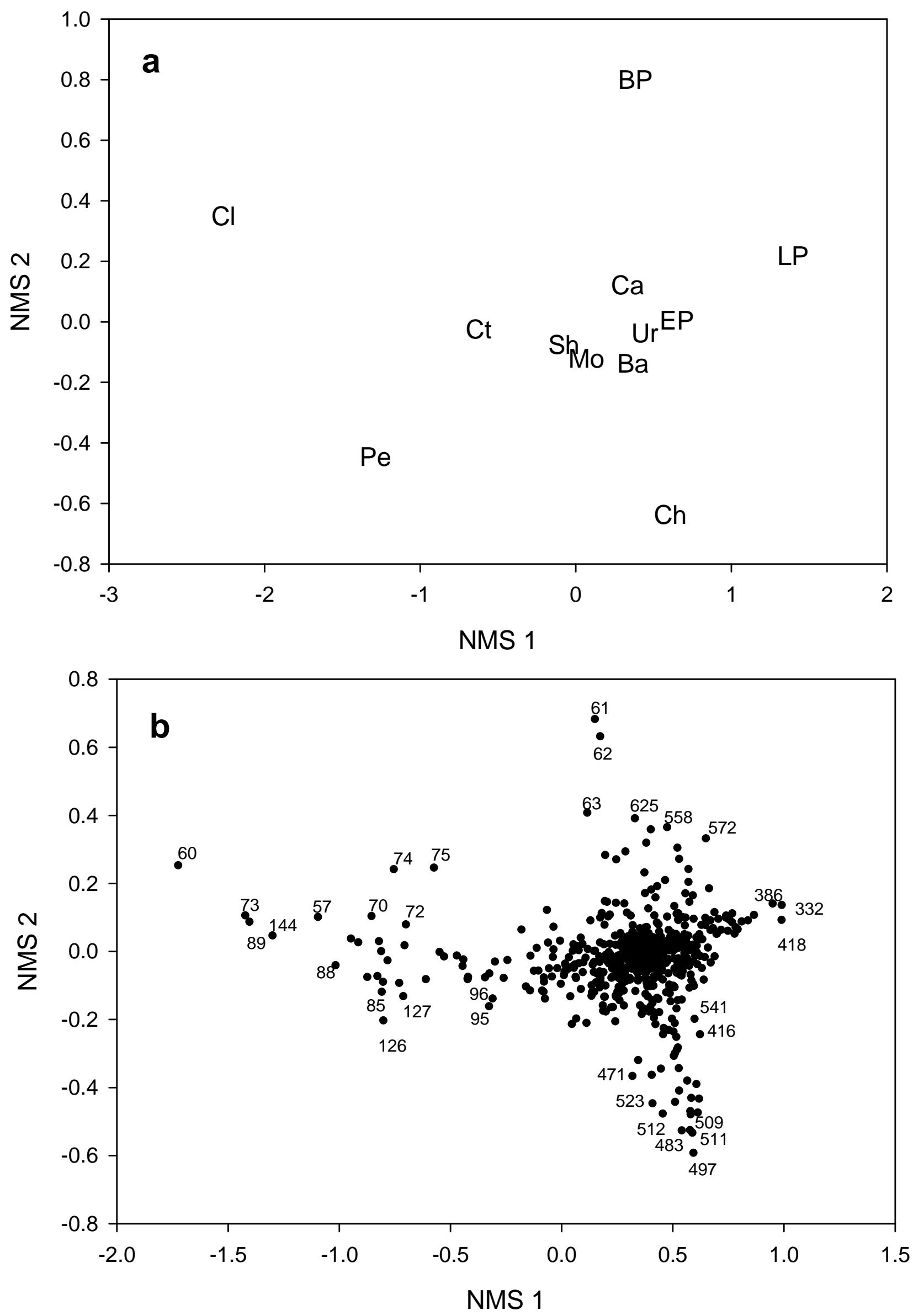

Figure 2 

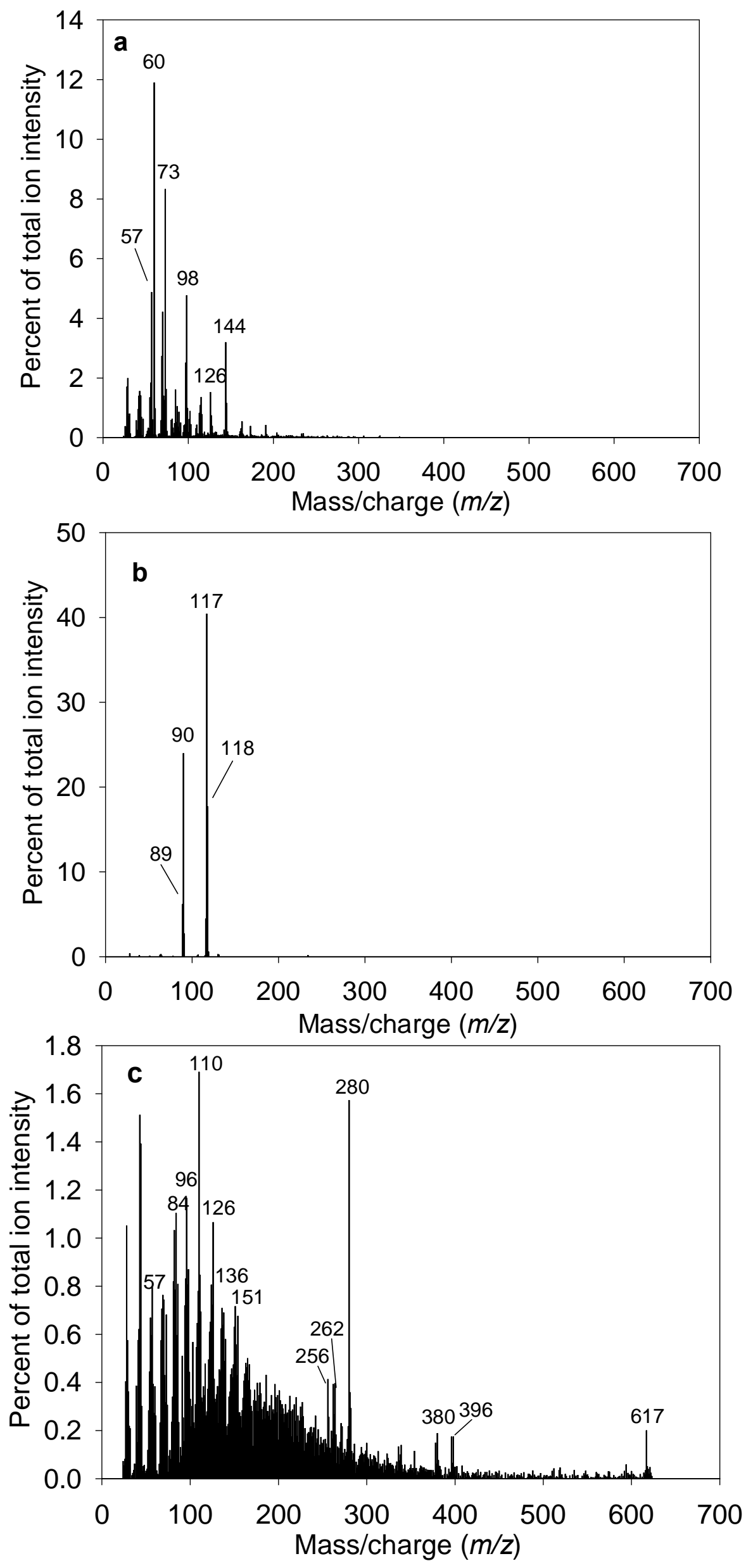

Figure 3 

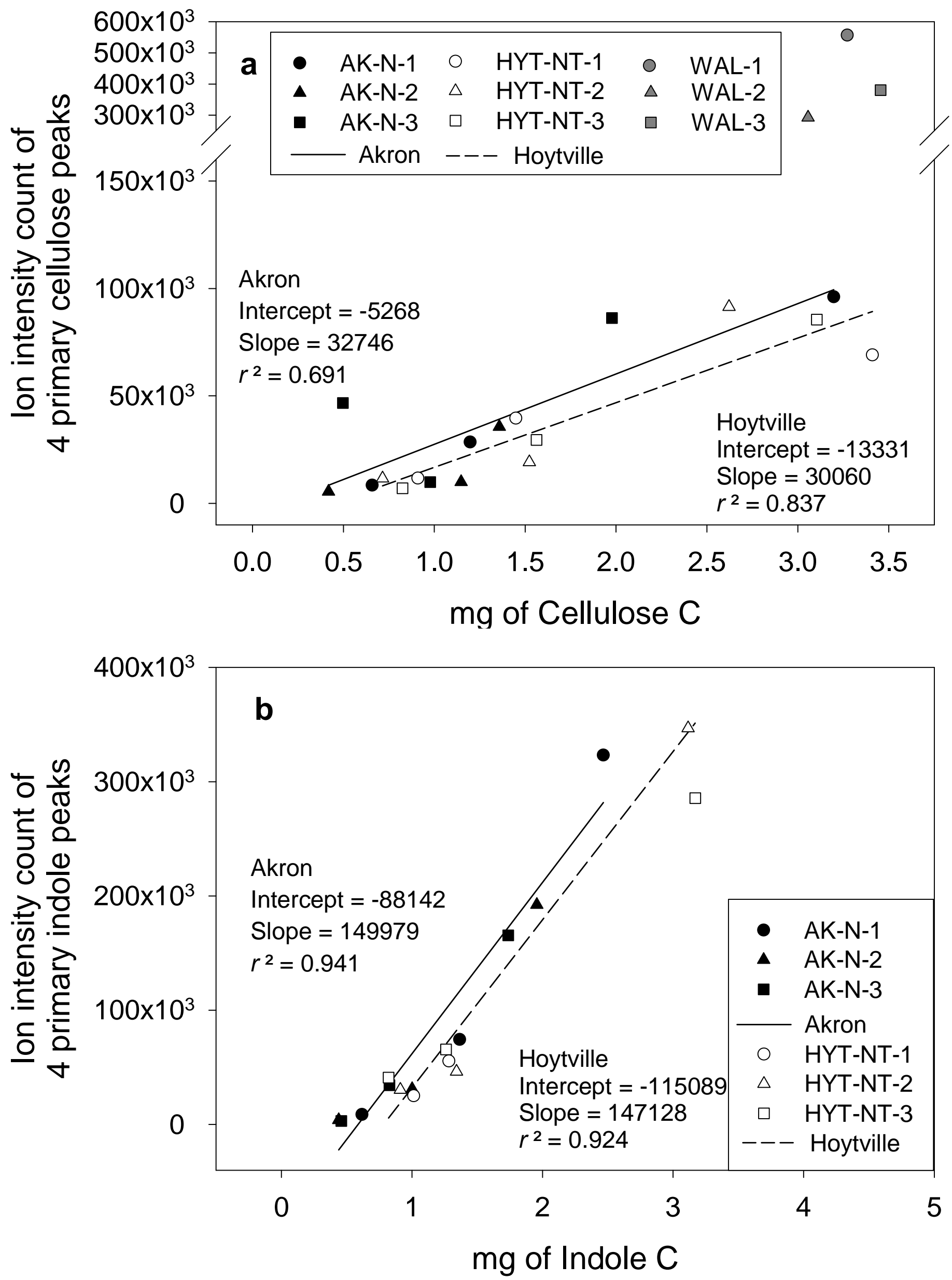

Figure 4 

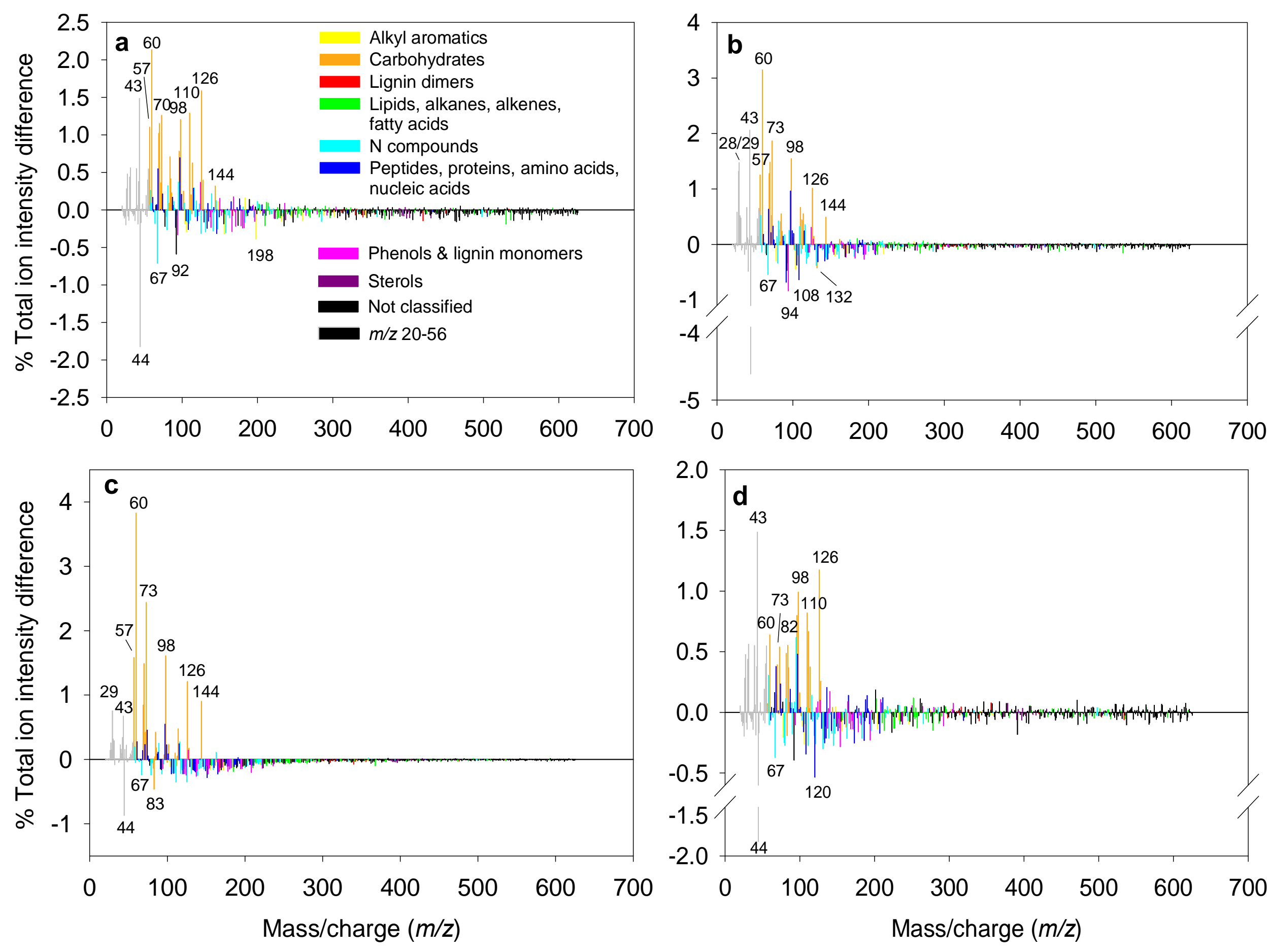

Figure 5 

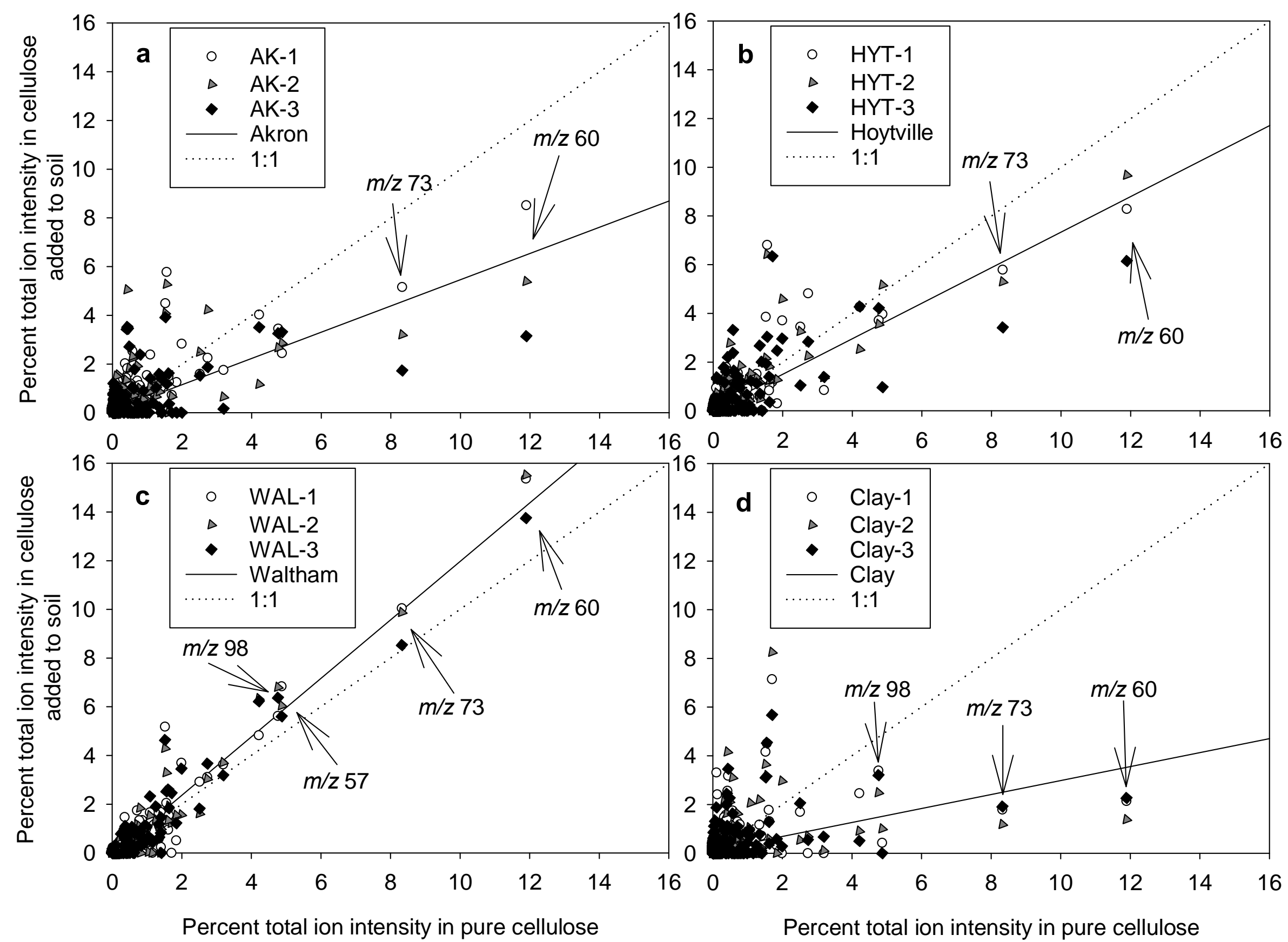

Figure 6 

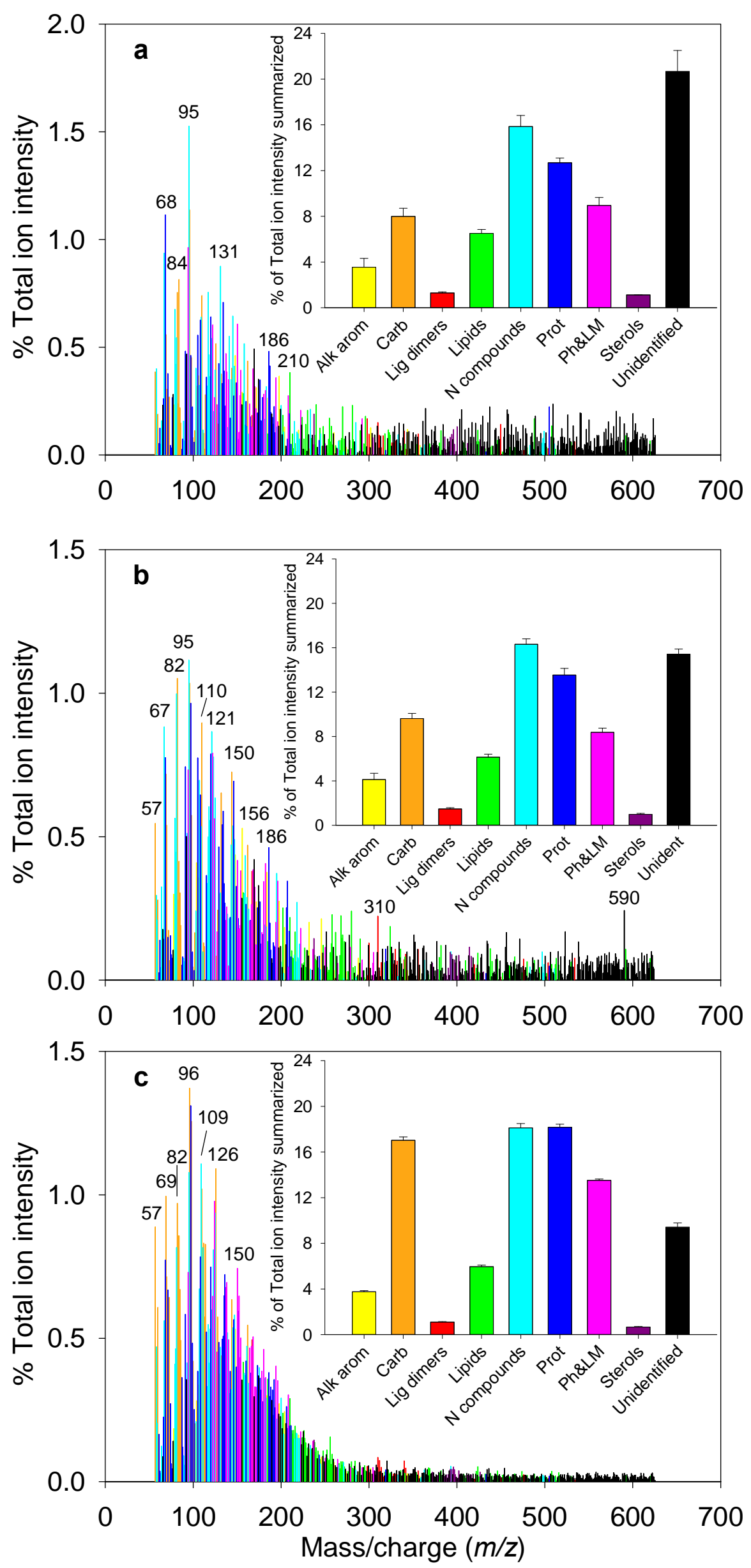

Figure 7 

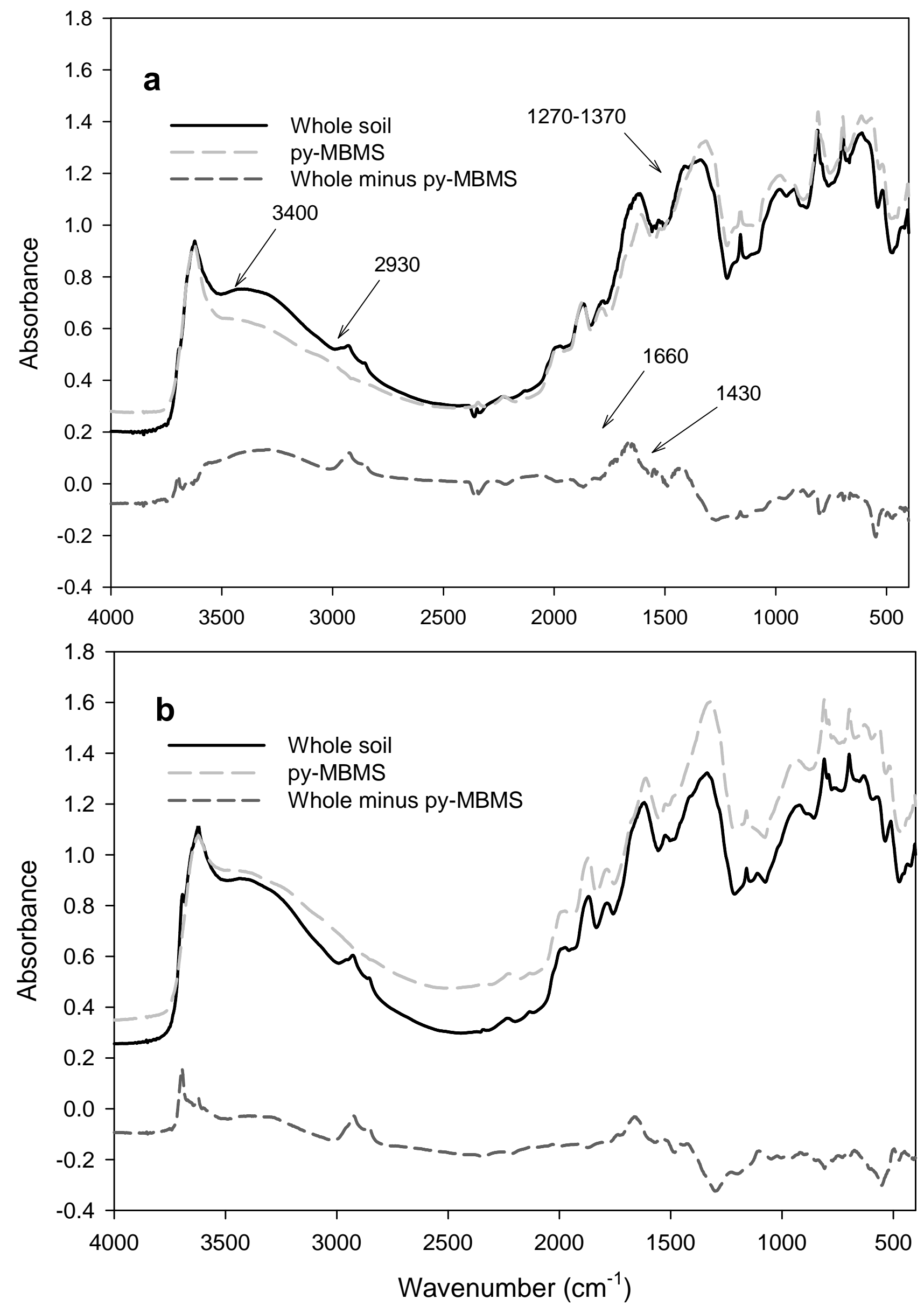

Figure 8 